\title{
Overview of Current Therapeutics and Novel Candidates Against Influenza, Respiratory Syncytial Virus, and Middle East Respiratory Syndrome Coronavirus Infections
}

\author{
Mohammad Amin Behzadi and Victor H. Leyva-Grado* \\ Department of Microbiology, Icahn School of Medicine at Mount Sinai, New York, NY, United States
}

\section{OPEN ACCESS}

Edited by:

Daniel Roberto Perez,

University of Georgia,

United States

Reviewed by:

Luis Martinez-Sobrido,

University of Rochester,

United States

Hana Maria Dobrovolny,

Texas Christian University,

United States

*Correspondence:

Victor H. Leyva-Grado

victor.leyva-grado@mssm.edu

Specialty section: This article was submitted to

Virology,

a section of the journal

Frontiers in Microbiology

Received: 04 March 2019

Accepted: 28 May 2019

Published: 19 June 2019

Citation:

Behzadi MA and Leyva-Grado VH

(2019) Overview of Current

Therapeutics and Novel Candidates

Against Influenza, Respiratory

Syncytial Virus, and Middle East

Respiratory Syndrome

Coronavirus Infections.

Front. Microbiol. 10:1327.

doi: 10.3389/fmicb.2019.01327
Emergence and re-emergence of respiratory virus infections represent a significant threat to global public health, as they occur seasonally and less frequently (such as in the case of influenza virus) as pandemic infections. Some of these viruses have been in the human population for centuries and others had recently emerged as a public health problem. Influenza viruses have been affecting the human population for a long time now; however, their ability to rapidly evolve through antigenic drift and antigenic shift causes the emergence of new strains. A recent example of these events is the avian-origin $\mathrm{H} 7 \mathrm{~N} 9$ influenza virus outbreak currently undergoing in China. Human H7N9 influenza viruses are resistant to amantadines and some strains are also resistant to neuraminidase inhibitors greatly limiting the options for treatment. Respiratory syncytial virus (RSV) may cause a lower respiratory tract infection characterized by bronchiolitis and pneumonia mainly in children and the elderly. Infection with RSV can cause severe disease and even death, imposing a severe burden for pediatric and geriatric health systems worldwide. Treatment for RSV is mainly supportive since the only approved therapy, a monoclonal antibody, is recommended for prophylactic use in high-risk patients. The Middle East respiratory syndrome coronavirus (MERS-CoV) is a newly emerging respiratory virus. The virus was first recognized in 2012 and it is associated with a lower respiratory tract disease that is more severe in patients with comorbidities. No licensed vaccines or antivirals have been yet approved for the treatment of MERS-CoV in humans. It is clear that the discovery and development of novel antivirals that can be used alone or in combination with existing therapies to treat these important respiratory viral infections are critical. In this review, we will describe some of the novel therapeutics currently under development for the treatment of these infections.

Keywords: antiviral, influenza, respiratory syncytial virus, MERS-coronavirus, novel therapeutic agents

\section{INTRODUCTION}

Respiratory viral infections are of global public health concern because they are the most common cause of symptomatic disease leading to a heavy economic burden due to an increased number of sick days (Borchardt and Rolston, 2012; Kim et al., 2017). In addition, respiratory diseases are one of the most common causes of mortality in developing countries (Ferkol and Schraufnagel, 2014). 
Among the two leading causes of respiratory virus infection are influenza (A and B) viruses and the respiratory syncytial virus (RSV) (Amarelle et al., 2017; Heylen et al., 2017; Yip et al., 2018). Most cases are observed in infants and children although the elderly and the immunocompromised are also at high risk of getting infected and develop severe disease (Jorquera and Tripp, 2017).

While influenza viruses and RSV circulate seasonally between beginning of fall and early spring, the increased numbers of avian influenza (H7N9) in China including highly pathogenic (HP) strains of the virus, the continued outbreaks of the HP avian influenza (HPAI) H5N1 viruses, novel variants of seasonal influenza viruses (H3N2var), and the emergence of the Middle East respiratory syndrome coronavirus (MERS-CoV) highlight the serious and important need for developing novel, more effective antiviral therapies (Zumla et al., 2016; International Society for Influenza and other Respiratory Viral Diseases, 2018). This review article focuses on therapies currently under development for treatment of influenza, RSV, and MERS-CoV infections. We will briefly review drugs that have been approved by the United States Federal Drug Administration (FDA) and then drugs that are in clinical trials (Figure 1). When available, the clinical trial identifier is included.

\section{INFLUENZA VIRUS}

Influenza virus is a negative sense, segmented RNA virus that presents a substantial burden to human health. Despite the availability of successful vaccines and antivirals, infection with seasonal influenza viruses is still the cause of 3-5 million cases of severe illnesses and up to 300-650 thousand deaths worldwide (World Health Organization, 2017). In the US alone, it is estimated that seasonal influenza affects up to 9 million people a year resulting in 12,000-56,000 deaths annually (Centers for Disease Control and Prevention, 2018c). The economic burden is estimated to be in the tens of billions of dollars (Putri et al., 2018). In addition, pandemic influenza outbreaks emerge at unpredictable intervals causing increased morbidity, mortality, and a negative economic impact (Erbelding et al., 2018).

\section{Currently Federal Drug Administration- Approved Anti-influenza Antivirals}

Briefly, these drugs can be divided in three groups: the M2 ion channel blockers, the neuraminidase inhibitors (NAIs), and the virus polymerase inhibitors. Amantadine and rimantadine are adamantane derivatives that inhibit viral replication by blocking the proton conductivity of the M2 ion channel preventing delivery of the virus ribonucleoprotein in the cytoplasm (Schnell and Chou, 2008; Ison, 2017). These compounds are specific for influenza A viruses since the M2 protein of influenza B viruses is structurally different (Wang et al., 2009; Pielak and Chou, 2011). In recent past seasons, surveillance studies reported high levels of resistance (>99\%) to adamantanes among circulating influenza $\mathrm{A}(\mathrm{H} 3 \mathrm{~N} 2)$ and influenza $\mathrm{A}(\mathrm{H} 1 \mathrm{~N} 1) \mathrm{pdm} 09$ viruses, and the centers for disease
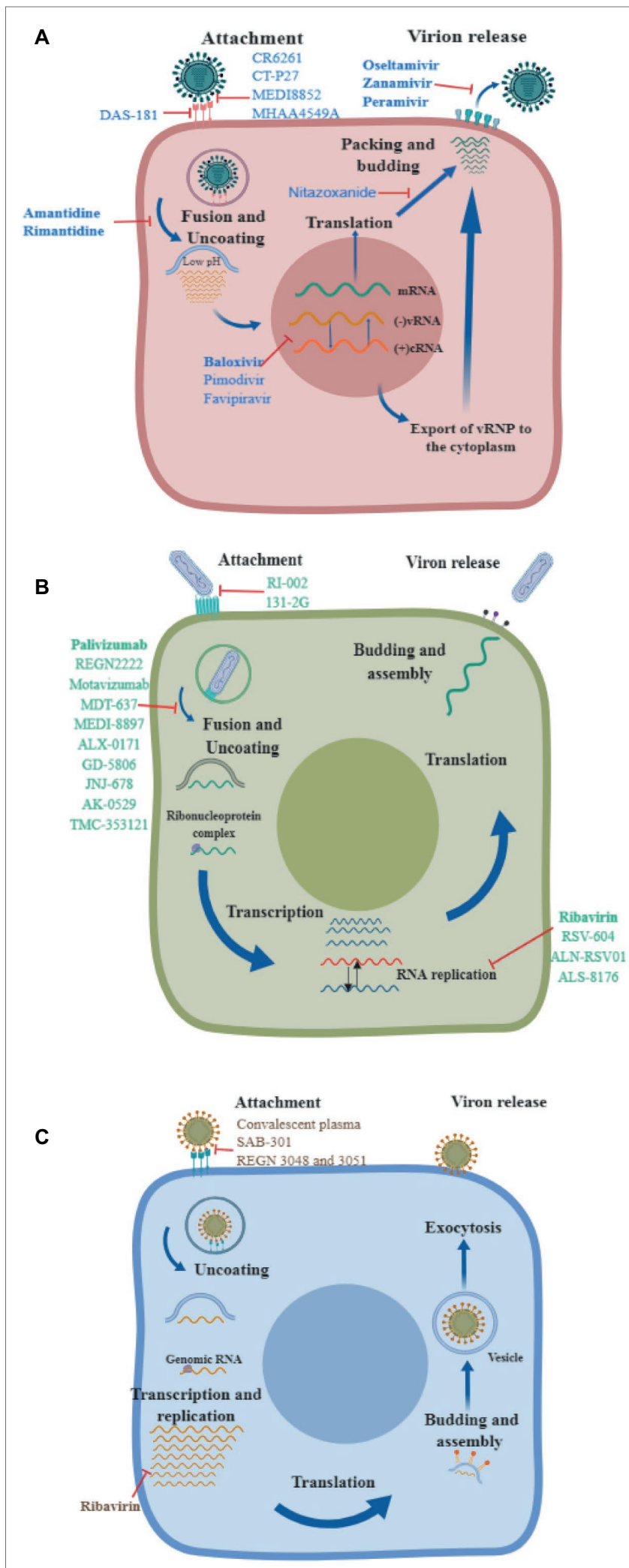

FIGURE 1 | Mechanisms of action of different antivirals. A diagram of the virus life cycle of (A) influenza virus, (B) respiratory syncytial virus, and (C) Middle East respiratory syndrome coronavirus, indicating where each therapeutic exerts its antiviral activity. Drugs approved by the FDA are shown in bold. 
control and prevention (CDC) does not recommend these compounds for antiviral treatment or chemoprophylaxis of currently circulating influenza A viruses (Centers for Disease Control and Prevention, 2018a). Development of NAI started in the early 1970s with derivatives of 2-deoxy-2,3-dehydro-Nacetylneuraminic acid (Palese et al., 1970), although it was not until 1999 that the first NAI was approved for use in humans (Chaudhuri et al., 2018). The NAI binds to the neuraminidase of the virus and prevents its cleavage, thus inhibiting the release of new virus particles (Ison, 2017). NAIs currently approved by the FDA include: oseltamivir, zanamivir, and peramivir. Oseltamivir acid is a pro-drug indicated for oral administration. Once in the gastrointestinal tract, the pro-dug is rapidly cleaved to the active metabolite, oseltamivir carboxylate (Kim et al., 2017). Due to poor oral bioavailability, zanamivir is approved for inhalation delivery with intravenous administration only available by compassionate use (Ison, 2017; Shaw, 2017). Peramivir also has poor oral bioavailability; therefore, it has been approved for intravenous administration only. Because the drug reaches high concentrations in plasma and respiratory tissues, it has been approved as a single-dose infusion. One of the inherit problems of these drugs is that, in order to be effective, treatment should start within $48 \mathrm{~h}$ post-exposure. Antiviral resistance to oseltamivir, zanamivir, and peramivir is very low in currently circulating influenza virus strains, although this can change because several clusters of oseltamivir resistance have been detected in Japan, Australia, and China (Takashita et al., 2015; Alame et al., 2016; Koszalka et al., 2017). Also known as S-033188, baloxavir marboxil $\left(\mathrm{Xofluza}^{\circledR}\right)$ is a pro-drug that is hydrolyzed in vivo to S-033447, the active form that selectively inhibits cap-dependent endonuclease, preventing the initiation of mRNA synthesis of the influenza virus (Takashita et al., 2018). This is a potent small molecule that shows activity against several influenza A viruses, including oseltamivir-resistant viruses as well as B viruses (Noshi et al., 2018). Preclinical studies demonstrated that treated mice infected with influenza virus were protected from clinical signs and mortality even in a delay of treatment approach (treatment started 4 days post-infection). Furthermore, a subtherapeutic dose of baloxavir in combination with oseltamivir also protected mice from infection and mortality (Fukao et al., 2018). In addition, studies in mice infected with avian influenza viruses such as $\mathrm{H} 5 \mathrm{~N} 1$ or $\mathrm{H} 7 \mathrm{~N} 9$ also demonstrated protection after oral administration with baloxavir (Uehara et al., 2016). A clinical study (NCT02954354) aimed to compare the efficacy of baloxavir with a placebo or oseltamivir in healthy patients infected with influenza demonstrated that the drug was well tolerated and was associated with a significant reduction in viral load compared to the oseltamivir group. Time of alleviation of symptoms was similar to oseltamivir. The currently undergoing clinical program for this drug includes phase 3 clinical trials to determine safety, pharmacokinetics, and efficacy in healthy pediatric participants aged less than 1 year (NCT03653364) or in pediatric patients with influenza-like symptoms (NCT03629184) and a study to assess efficacy and safety of baloxavir in combination with standard-of-care neuraminidase inhibitor in hospitalized participants with severe influenza (NCT03684044). These studies are currently recruiting and expected to be concluded in spring 2020. In Japan, baloxavir has been approved for the treatment of adult and infant patients infected with influenza; while in the US, the drug has just been approved by the FDA for the treatment of acute, uncomplicated influenza in people aged 12 years and older (Food and Drug Administration, 2018). The emergence of resistant variants to polymerase inhibitors has been observed and it is conferred by an I38T mutation in the PA polymerase (Jones et al., 2018). In the same study, a novel mutation conferring resistance (E23K) was also observed. Both mutations have been encountered during clinical trials for baloxavir (Hayden et al., 2018).

\section{Promising Drug Candidates in the Pipeline}

Given the inherit limitations of these currently approved compounds and the potential risk for the arising of antiviral resistance, there is still an urgent need for developing new anti-influenza drugs. These novel drugs should have some (ideally all) of the following characteristics: effective when delivered late in infection, low propensity for developing antiviral resistance, broad activity (influenza A and B), improved effectiveness compared to the standard of care, and can be easily administered in uncomplicated as well as complicated cases of influenza (Koszalka et al., 2017; Shaw, 2017). Next, we will summarize the most advanced (phase 2 and 3 clinical trials), promising drug candidates.

\section{VIRAL TARGETING CANDIDATES}

\section{Antibodies}

New and more efficient technologies for the production of monoclonal antibodies (mAbs) have stimulated the development of novel mAbs-based therapies for influenza and other infectious diseases (Jin et al., 2017). A number of broadly neutralizing mAbs targeting the conserved stalk region of the influenza virus hemagglutinin (HA) molecule are currently under development. In addition, a non-neutralizing $\mathrm{mAb}$ targeting the virus matrix protein is also in clinical trials.

\section{CR6261 and CR8020}

CR6261 is directed against a highly conserved helical region in the membrane-proximal stalk of hemagglutinin. In vitro studies on this class of $\mathrm{mAbs}$ demonstrated neutralization activity across a broad spectrum of influenza A subtypes. CR6261 is protective in mice against lethal doses of $\mathrm{H} 1 \mathrm{~N} 1$ and H5N1 viruses (Koudstaal et al., 2009). A challenge study successfully demonstrated both therapeutic and prophylactic efficacy in the ferret model against a lethal dose of an $\mathrm{H} 5 \mathrm{~N} 1$ virus (Friesen et al., 2010). A clinical trial phase 2 (NCT02371668) aimed to determine if the CR6261 reduces flu disease in people treated with this drug versus a placebo has concluded but results are still not available. CR8020 targets an immunosubdominant, relatively conserved membrane-proximal stalk region of hemagglutinin. The $\mathrm{mAb}$ is active against group 2 
influenza viruses and has been shown to have neutralization activity against $\mathrm{H} 3, \mathrm{H} 7$, and $\mathrm{H} 10$ subtypes both in vitro and in vivo (Ekiert et al., 2011). A phase 2a trial to evaluate the protective efficacy and safety of CR8020 in an influenza challenge model was completed in 2014 (NCT01938352). Unfortunately, a recent study showed that CR8020 targets a region of the HA stalk that is prone to escape, therefore escape mutants are likely to arise (Tharakaraman et al., 2014).

\section{CT-P27}

This product contains two distinct but complementary mAbs that have shown broad efficacy in vitro and in vivo against different group 1 and group 2 influenza viruses. A phase 2a clinical trial (NCT02071914) was conducted to evaluate the efficacy and safety of CT-P27 in an influenza challenge model. The study concluded in July 2014, however no results were reported. Currently recruiting, a phase $2 \mathrm{~b}$ clinical trial (NCT03511066) is aimed to evaluate the efficacy and safety of the mAbs combo in comparison to placebo in subjects with acute uncomplicated influenza $\mathrm{A}$ infection.

\section{MEDI8852}

This is a potent, broadly neutralizing investigational human IgG1 mAb targeting a highly conserved stalk region of the HA protein. MEDI8852 has been reported to effectively neutralize all known influenza A HA subtypes (Kallewaard et al., 2016). Preclinical studies in animal models have shown efficacy in protecting against $\mathrm{H} 5 \mathrm{~N} 1$ influenza virus lethal challenges when used alone or in combination with oseltamivir (Paules et al., 2017). A phase 2a study (NCT02603952) to evaluate the safety of MEDI8852 in adults with acute, uncomplicated influenza was recently concluded and results demonstrated an acceptable safety profile in this group of patients. In 2016, MEDI8852 received Fast Track designation by the FDA that allows the drug an expedite development and review (Ali et al., 2018).

\section{MHAA4549A}

This is a human monoclonal IgG1 antibody containing a $\mathrm{VH}$ 3-30 59 heavy chain paired with a Vк1-15 light chain (McBride et al., 2017). MHAA4549A targets a highly conserved epitope on the stalk region of HA and is capable of neutralizing all tested seasonal human influenza A strains (Nakamura et al., 2013). Two mechanisms of action have been described for this $\mathrm{mAb}$, one by binding the HA to avid virus infectivity and two by antibody-dependent cell-mediated cytotoxicity to increase killing of infected cells (McBride et al., 2017). Preclinical studies demonstrated efficacy in the mouse model against a diverse group of influenza viruses including group 1 and group 2 strains even when administered $72 \mathrm{~h}$ post-infection. In addition, synergism was observed when administered with oseltamivir at $48 \mathrm{~h}$ post-infection. Finally, studies in ferrets demonstrated protection against an H5N1 HPAI virus challenge (Nakamura et al., 2013). A few clinical trials have been conducted to evaluate safety, pharmacokinetics, and efficacy of MHAA4549A alone or in combination with oseltamivir (Lim et al., 2016; McBride et al., 2017; Deng et al., 2018). Results established that the $\mathrm{mAb}$ is well tolerated with a half-life similar to other human antibodies ( 23 days) but with a nonlinear nasal pharmacokinetics (McBride et al., 2017; Deng et al., 2018). Furthermore, treatment significantly reduced viral loads (McBride et al., 2017). The most recent clinical trial (NCT02293863) aimed to investigate the safety and clinical activity of a single intravenous (IV) dose of MHAA4549A in adult participants hospitalized with severe influenza $\mathrm{A}$ in combination with oseltamivir was recently concluded and results indicated no advantage on any of the primary clinical outcomes evaluated when compared with the standard of care. Furthermore, no significant differences were observed in any of the virologic outcomes evaluated including viral shedding or peak of virus load.

\section{Virus Polymerase Inhibitors Pimodivir}

This is a novel, non-nucleoside polymerase inhibitor that targets the PB2 subunit of influenza A viruses. Targeting the PB2 avoids docking of the 7-methyl GTP cap structure, thus preventing viral RNA synthesis (Clark et al., 2014; Boyd et al., 2015). The early activity of pimovidir in the cell cycle has shown to improve cell viability compared to oseltamivir (Byrn et al., 2015). Furthermore, it is active against a diverse group of influenza A viruses including the H1N1pdm, H5N1, and H7N9 (Byrn et al., 2015). Preclinical studies in mice demonstrated protection against a lethal challenge even when given 4 days post-infection with H1N1pdm or H5N1 viruses (Byrn et al., 2015). Further studies also showed protection against a lethal challenge using an H3N2 virus (Smee et al., 2016). Studies using pimodivir and oseltamivir suggest a potential benefit for a combination therapy (Trevejo et al., 2018). A phase $2 \mathrm{~b}$ clinical study (NCT02342249) treatment with pimodivir significantly decreased viral load over 7 days versus placebo, in adult patients with acute, uncomplicated seasonal influenza A. Recently, pimodivir has received FDA Fast Track designation due to its potential to address an unmet medical need in those who develop influenza A infection complications. A phase 3 clinical trial (NCT03381196) aimed to evaluate the efficacy and safety of pimodivir in combination with oseltamivir in adults at risk of developing complications is currently recruiting patients and it is expected to be concluded in October 2019.

\section{Favipiravir}

Formerly known as T-705, this substituted pyrazinecarboxamide derivative is an inhibitor of the influenza virus polymerase. As a purine nucleoside analog, favipiravir directly inhibits the activity of the RNA-dependent RNA polymerase (Furuta et al., 2005) and it has broad-spectrum activity against all influenza subtypes including those resistant to neuraminidase and M2 inhibitors (Furuta et al., 2017). Preclinical studies demonstrated the broad antiviral spectrum of this compound against different human and avian influenza $\mathrm{A}$ and $\mathrm{B}$ viruses including avian influenza viruses $\mathrm{H} 5 \mathrm{~N} 1$ and H7N9 (Sidwell et al., 2007; Watanabe et al., 2013) where it has shown protection and reduction of virus titers in the infected mice. Furthermore, mice treated with favipiravir had a better outcome 
after an H7N9 infection compared to mice treated with neuraminidase inhibitors (Watanabe et al., 2013). Combination therapy studies found that this drug works synergistically with neuraminidase inhibitors to improve lung virus titers, body weight loss, and survival in mice infected with a pandemic H1N1 influenza virus (Tarbet et al., 2012) or with an avian influenza virus H5N1 (Smee et al., 2010). Favipiravir is approved in Japan, but its use is restricted to patients infected with an influenza virus resistant to NAI or in the event of a pandemic (Toyama Chemical Co. Ltd). These conditions have been put in place due to concerns of teratogenicity, which have been identified in animal experiments. A couple of phase 3 clinical trials aimed to determine the efficacy and safety of favipiravir for the treatment of uncomplicated influenza infection in adults have been completed but the results have not been published yet. A new phase 2 a clinical trial study to determine the pharmacokinetics of favipiravir in patients with severe influenza is reported as active but not currently recruiting with estimated study completion date of March 2019 (NCT03394209). This is a very promising broad-spectrum anti-influenza antiviral that also has a broad antiviral activity against several other RNA viruses (Davidson, 2018). A couple of caveats may limit the use of this antiviral to compassionate use or in the case of emerging or re-emerging viruses for which a treatment is not available. Favipiravir has the potential for teratogenicity and embryotoxicity and is the reason why it has conditional approval in Japan (Furuta et al., 2017). A study of samples obtained for a clinical trial tested the emergence of mutations in viruses obtained from paired patients before and 1 or 2 days after the initiation of treatment showed the emergence of amino acid substitutions in the RNA polymerase subunits. Although these mutations did not significantly reduce the susceptibility to favipiravir (Takashita et al., 2016), in vitro escalation studies showed that influenza viruses can adapt to low concentration of the compound which highlights the potential for some influenza virus strains to possibly develop resistance (Ormond et al., 2017).

\section{HOST-TARGETING CANDIDATES}

\section{Fludase}

Also known as DAS-181, this is a recombinant sialidase composed of the catalytic domain of a bacterial sialidase (Actinomyces viscosus) and the epithelium-anchoring domain of the human protein amphiregulin (Malakhov et al., 2006). In the human respiratory tract, cell surface sialic acids are the primary receptors for binding and entry of influenza viruses. Fludase works by removing sialic receptors from the airway epithelium, therefore preventing viral entry into cells of the respiratory epithelium (Triana-Baltzer et al., 2011). Preclinical in vitro studies show that fludase is a broad-spectrum anti-influenza antiviral with potent antiviral activity against human and avian influenza viruses with no cellular toxicity (Triana-Baltzer et al., 2009, 2010). In vivo studies showed that mice can be rescued from influenza infection after treatment with fludase, including after infection with highly pathogenic $\mathrm{H} 5 \mathrm{~N} 1$ and $\mathrm{H} 7 \mathrm{~N} 9$ viruses (Belser et al., 2007; Marjuki et al., 2014, 2015). In a randomized, double-blind, placebo-controlled phase 2 study conducted to determine the effective dose in healthy adult participants with laboratory-confirmed influenza (NCT01037205), it was observed that treatment with fludase significantly reduces viral load and viral shedding after multiple doses. In addition, no significant adverse effects were observed in the patients that received the treatment (Moss et al., 2012). In a phase 1 clinical trial (NCT01651494), it was observed that in longer treatments (more than 7 days), patients developed antibodies against the compound leading to a reduced efficacy (Zenilman et al., 2015).

\section{Nitazoxanide (Alina ${ }^{\circledR}$ )}

Nitazoxanide (NTZ) was originally developed and licensed as an antiprotozoal drug for the treatment of enteritis caused by Cryptosporidium and Giardia infections. Nitazoxanide is a thiazolide compound that is rapidly deacetylated in the blood to the active metabolic form tizoxanide (Rossignol, 2009). In addition to its antiparasitic activity, this compound has shown activity against a broad range of viruses including influenza viruses (Belardo et al., 2015; Tilmanis et al., 2017; Stachulski et al., 2018). The mechanism of action against influenza virus is achieved by impairing the trafficking of the viral hemagglutinin (HA) from the endoplasmic reticulum to the Golgi apparatus and by blocking HA terminal glycosylation leading to block maturation of the HA (Rossignol et al., 2009). Preclinical studies demonstrated an antiviral activity against different strains of influenza $A$, and $B$ viruses in vitro including avian influenza viruses (Sleeman et al., 2014). There are not published studies of the antiviral efficacy of NTZ in animal models, although extensive pharmacological testing has been performed in animals (Koszalka et al., 2017). Nitazoxanide is an example of a repurposed drug with a lot of studies in humans, which is facilitating the advancement of this drug as a treatment for influenza virus infection (Rossignol, 2009). A phase 2b/3 clinical trial (NCT01227421) aimed to determine the safety and efficacy of NTZ in the treatment of acute uncomplicated influenza established that treatment with $300 \mathrm{mg}$ twice a day for 5 days was well tolerated and it was associated with a reduction of symptoms and infectious viral load (Haffizulla et al., 2014). A phase 3 study (NCT03336619) to evaluate the efficacy and safety of 300-mg nitazoxanide tablets (Stachulski et al., 2018) in the treatment of uncomplicated influenza was concluded in March 2019 but results have not been posted.

\section{RESPIRATORY SYNCYTIAL VIRUS}

Respiratory syncytial virus is the most commonly identified cause of acute lower respiratory tract infection in infants, children, immunocompromised adults, and the elderly (Zorc and Hall, 2010; Griffiths et al., 2017). Since the first isolation of the virus from chimpanzees in 1956 (Morris et al., 1956), extensive research 
has been conducted in epidemiology, diagnosis, and animal models for the infection, but there is no vaccine and only two approved antivirals available against the virus (Xing and Proesmans, 2019).

RSV is a non-segmented virus with negative sense singlestranded RNA genome encoding 11 proteins. Out of those, two surface transmembrane proteins, $G$ and $F$, have been shown to play a key role in RSV binding and fusion, respectively. The virus is classified into two subtypes: A and $\mathrm{B}$, with about $50 \%$ genetic diversity in the G gene and $10 \%$ differences in the F gene (Tian et al., 2017; Xing and Proesmans, 2019). Due to less antigenic variability of the $F$ protein compared with the G protein, this protein is the main target of research for developing antivirals as well as anti-RSV vaccines (Taleb et al., 2018).

\section{Currently Federal Drug Administration- Approved Anti-Respiratory Syncytial Virus Antivirals}

There are only two RSV antiviral drugs approved by the FDA for the treatment or prevention of serious respiratory tract infections caused by RSV: aerosolized ribavirin for treatment and palivizumab (Synagis ${ }^{\circledR}$ ) for prophylaxis.

The guanosine analog ribavirin is a broad-spectrum antiviral agent with activity against RSV and other RNA viruses such as hepatitis C and Zika viruses (Antonini et al., 2018; Kim et al., 2018; Zhurilo et al., 2018). The beneficial effect of this drug in inhibiting RSV replication was demonstrated in several studies. Ribavirin showed antiviral activity against RSV and reduced RSV lung titers in infected cotton rats (Bonavia et al., 2011). Similarly, significant clinical benefits have been observed in children treated with aerosolized ribavirin early in infection (Devincenzo, 2000). However, the clinical application of ribavirin is limited because of its nonspecific anti-RSV activity, risks for potential toxicity, and relatively high cost (Sun et al., 2013).

Palivizumab is a humanized monoclonal antibody found to have strong RSV-neutralizing capability against a range of RSV strains. The palivizumab 24-aa epitope structure on the RSV F protein is well characterized (Schickli et al., 2015). The drug has been shown to be effective in preventing RSV-related hospitalizations in children (Frogel et al., 2008). Although the efficacy of this antiviral against RSV infection is proven, due to the considerable cost of palivizumab, the usage is limited to the high-risk populations (Shahabi et al., 2017) including infants and young children (Centers for Disease Control and Prevention, 2018b).

\section{PROMISING NEW ANTIVIRAL CANDIDATES IN THE PIPELINE}

In recent years, in addition to the FDA-approved RSV antivirals, a number of alternative strategies against RSV including new recombinant antibodies, nanobodies, small molecules such as fusion inhibitors, nucleoprotein inhibitors, nucleoside analogs, and non-nucleoside inhibitors are being developed.

\section{Antibodies}

Intravenous polyclonal immunoglobulin (IVIG) is a preparation of human serum that contains high titers of neutralizing antibodies against the virus. Usage of IVIG in severe RSV infections in high-risk children significantly reduced the rate of hospitalizations due to related respiratory infections (The PREVENT Study Group, 1997). Currently, new recombinant mAbs against RSV are in different stages of development.

\section{RI-001 and RI-002}

These are aqueous intravenous polyclonal human immunoglobulin $\mathrm{G}(\mathrm{IgG})$ from pools of source plasma of screened healthy adult donors with high levels of RSV-neutralizing antibodies. The results of a phase 1 and a 2 study on RI-001 and RI-002, respectively, demonstrated that the preparation met acceptable pharmacokinetic and safety criteria, and achieved a fold-change increase in titer of anti-RSV neutralizing antibodies in patients (Wasserman et al., 2017).

\section{REGN2222}

REGN2222 is a fully human IgG1 mAb produced in VelocImmune mice that binds specifically to the F protein of RSV. Preclinical studies in cotton rats demonstrated that REGN2222 is effective at reducing RSV viral replication in the lungs (Gurnett-Bander et al., 2016). Although the results of two clinical trials in phase 1 in healthy adults showed that the antibody was well tolerated and it had a half-life longer than typical IgG1 mAbs with low immunogenicity (Sivapalasingam et al., 2015), the results of a recent phase 3 trial in preterm infants revealed that this $\mathrm{mAb}$ did not meet its primary endpoint of preventing RSV.

\section{MEDI8897}

MEDI8897 is a recombinant human IgG1א mAb with an engineered $\mathrm{Fc}$ region to have a longer serum half-life and designed for prevention of lower respiratory tract illness (LRTI) caused by RSV. The antibody binds to the prefusion conformation of the F protein of RSV. The results of placebo-controlled studies in healthy adults and healthy preterm infants showed an increase in the mean half-life of MEDI8897. Moreover, the safety profile of MEDI8897 was similar to placebo (Griffin et al., 2017; Domachowske et al., 2018). To evaluate the efficacy of this $\mathrm{mAb}$ in preventing infection, further clinical studies are still needed in the target population of infants entering their first RSV season.

\section{ALX-0171}

ALX-0171, the first nanobody developed for treatment of RSV infection, is a trivalent nanobody $(42 \mathrm{kDa})$ that binds the antigenic site II of the RSV F protein and neutralizes both subtypes of RSV. In vitro neutralization efficiency of ALX-0171 is greater than palivizumab (Detalle et al., 2016). Preclinical studies in cotton rats and neonatal lambs have indicated that ALX-0171 is highly effective in reducing both nasal and lung RSV titers (Hanton et al., 2012; Detalle et al., 2014). 
The results of phase 1 and 2 clinical studies demonstrated that inhaled ALX-0171 inhibited RSV replication and reduced viral load compared to placebo. ALX-0171 is currently in clinical trials (NCT03418571) to treat infants hospitalized with RSV infection (Van Heeke et al., 2017).

\section{mAb 131-2G}

$131-2 \mathrm{G}$ is a murine $\mathrm{mAb}$ that binds to the central conserved region of the RSV G protein and interferes with the attachment process by blocking the $\mathrm{G}$ protein from binding to CX3CR1 (Johnson et al., 2015). RSV-challenged mice studies showed that early treatment with this $\mathrm{mAb}$ reduced both pulmonary inflammation and lung virus titers (Haynes et al., 2009). Clinical studies are needed to evaluate the safety and efficacy of this antiviral in humans.

\section{Motavizumab}

Motavizumab is a recombinant humanized $\mathrm{mAb}$ that binds to a 24-residue, linear, conformational epitope FFL on the RSV F glycoprotein (Zhu et al., 2011). Preclinical studies in cotton rats demonstrated that the $\mathrm{mAb}$ decreased RSV titers more than 50 times in lungs in comparison to palivizumab ( $\mathrm{Wu}$ et al., 2007). Phase 1 and 2 clinical trials showed that motavizumab is well tolerated in healthy adults and premature infants as well as in high-risk children with chronic lung disease of prematurity (Abarca et al., 2009; O'Brien et al., 2015). The results of a recent phase 3 clinical trial to prevent serious RSV disease in healthy term infants indicated that motavizumab reduced the proportion of infants admitted to the hospital with RSV (O’Brien et al., 2015).

\section{Fusion Inhibitors (Small Molecules)}

Numerous studies have evaluated the virus-host interactions to determine the viral and host factors that contribute to replication of viruses. For RSV replication, both the co-receptors that become localized on the epithelium in response to virusmediated signals and the RSV F protein contribute to this process (Hotard et al., 2015). Most antiviral small molecules that bind to the F protein can block membrane fusion and viral penetration, and subsequently inhibit RSV replication (Battles et al., 2016).

\section{GS-5806}

GS-5806 is an orally bioavailable RSV fusion inhibitor that has been shown to prevent RSV entry by blocking the viruscell fusion process (Samuel et al., 2015). In a preclinical study conducted in cotton rats, an efficient bioavailability and penetration of the drug in lung tissue were observed. The results of a clinical study in healthy volunteers experimentally infected with RSV indicated that oral administration of GS-5806 resulted in reduction of viral load and disease severity (Mackman et al., 2015). More clinical trials have been completed in different populations including in RSV-infected hospitalized patients, lung transplant recipients, and in hematopoietic stem cell transplantation recipients, but the results are not available yet. Recently published results for phase $2 \mathrm{~b}$ trials in hospitalized adults with RSV did not show significant reduction in viral load or improvement of clinical outcomes to the disease (Hanfelt-Goade et al., 2018). To clarify the efficacy of this drug, further studies are required in infants and children.

\section{MDT-637}

MDT-637 (VP-14637) is a fusion inhibitor that has been shown to inhibit RSV entry to the cells. Both in vitro reports and preclinical studies in cotton rats demonstrated the anti-RSV activity of MDT-637. This compound is effective against both subtypes of RSV (Kim et al., 2017). The reformulated form of MDT-637, VP-14637, can be administered by powder inhaler with a quick delivery to the respiratory tract (Wyde et al., 2005). The results of phase 1 clinical trials indicated a safety and desirable pharmacokinetic profile of the drug in healthy adults (NCT01475305) (Kim et al., 2017).

\section{JNJ-53718678}

JNJ-678 is a potent RSV-specific fusion inhibitor that has been shown to act as an effective anti-RSV in vitro and in animal models (Roymans et al., 2014; Ackermann et al., 2016). Clinical studies in healthy adults assessed its antiviral efficacy as well as safety. It was shown that JNJ-53718678 reduced RSV viral load, respiratory infections' severity caused by RSV, and duration of the disease (Israel et al., 2016; Huntjens et al., 2017). Further studies are needed in infants and children to prove the antiviral activity of this anti-RSV candidate.

\section{AK-0529}

AK-0529 is a novel compound being developed to inhibit RSV replication by blocking viral entry into the target cells. A placebo-controlled phase 1 clinical trial showed that oral administration of this antiviral is well tolerated among healthy volunteers and meets the standard safety profile (Toovey et al., 2015). A phase 2 clinical trial in hospitalized infants infected with RSV is currently underway (NCT02654171).

\section{TMC353121}

TMC353121, a small substituted benzimidazole RSV fusion inhibitor, is an improved derivative of JNJ-2408068 [a compound with antiviral activity against both RSV A and B, but with long tissue retention times in animal models which created concerns and stopped its further development (Wyde et al., 2003; Bonfanti et al., 2007)].TMC353121, in contrast to JNJ-2408068, lacks the long tissue retention but maintains its high antiviral activity in vitro (Bonfanti et al., 2008). Using TMC353121 in preclinical studies in cotton rats (Rouan et al., 2010) and African green monkeys (Ispas et al., 2015) revealed a reduction in viral loads in a dose-dependent manner and in lung inflammation. Based on these data, TMC353121 could be a drug candidate for treatment of RSV infection; however, safety studies and more clinical evaluations are still needed. 


\section{Nucleoprotein Inhibitors}

One promising area of development revolves around inhibitors of RSV that target the virus nucleoprotein. RSV nucleoprotein is involved in virus assembly and it is crucial for the virus replication. Less genetic variation of this protein among RSV $\mathrm{A}$ and $\mathrm{B}$ subtypes makes it an amenable molecular target for development of anti-RSV compound (Collins et al., 2013).

\section{RSV-604}

RSV604 is a small molecule with submicromolar RSV activity that was discovered through chemical optimization of an RSV high-throughput screen hit (Chapman et al., 2007). It is effective against both RSV A and B replication at a postentry step. The antiviral mechanism of this compound is related to its binding to the RSV N protein and therefore inhibition of both RNA synthesis and the infectivity of released virus (Challa et al., 2015). A phase 2a clinical trial in stem cell transplant patients with RSV infection showed that following treatment with RSV604, plasma exposure reached the $90 \%$ effective concentration $\left(\mathrm{EC}_{90}\right)$. In addition, patients had a reduction in viral titers and RSV infection symptoms (Marty et al., 2007).

\section{ALN-RSV01}

ALN-RSV01 is a small interfering RNA (siRNA) with 19 nucleotides targeting a highly conserved region of the RSV nucleoprotein gene. This siRNA has shown to be effective in both prophylaxis and treatment models. Results of a preclinical study in mice indicate that treatment with ALN-RSV01 achieved up to 3-logs reduction in RSV lung titers in comparison to control groups (Lu et al., 2018). Intranasal administration of ALN-RSV01 in healthy volunteers inoculated with RSV showed a significant reduction of RSV infection in active drug recipients when compared to the placebo recipients group (DeVincenzo et al., 2010). In a phase 2 clinical trial conducted in lung transplant recipients with RSV infection, a good safety profile and positive benefits of this siRNA were observed in reducing the risk of bronchiolitis obliterans syndrome (Gottlieb et al., 2016). Further evaluations of this antiviral in naturally RSV-infected children and infants should be established.

\section{Nucleoside Analog and Non-nucleoside Inhibitors ALS-008176}

ALS-008176 (4 chloromethyl-2-deoxy-3,5-di-O-isobutyryl-2fluorocytidine) is a nucleoside RSV polymerase inhibitor with a high level of oral bioavailability. A preclinical study in African green monkeys infected with RSV and treated orally demonstrated an efficient antiviral activity (Deval et al., 2015). A clinical trial in healthy adults experimentally infected with RSV revealed shorter RSV RNA clearance time in the ALS-008176 treated group compared with placebo recipients, and the reduction in RSV viral load ranged from 73 to $88 \%$ in nasal washes of ALS-008176 treated individuals (DeVincenzo et al., 2015).

\section{MIDDLE EAST RESPIRATORY SYNDROME}

MERS is an emerging zoonotic disease caused by a virus called MERS coronavirus (MERS-CoV). This virus is an enveloped, single-stranded, positive sense RNA virus with a large genome (approximately $30 \mathrm{~kb}$ in length) belonging to the $\mathrm{C}$ lineage of Betacoronavirus (Enjuanes et al., 2016; Wernery et al., 2017).

The disease was first reported in 2012 in the Middle East and since then multiple introductions to the human population have occurred from the dromedary, the only known animal reservoir of MERS-CoV (Wernery et al., 2017; Jordan et al., 2018; Paden et al., 2018). The majority of the 2,374 cases reported up to date (World Health Organization, 2019) have occurred in Saudi Arabia (1983 cases). The disease has been reported in 27 countries from different continents with most of them associated with recent travel to the Arabic peninsula (Park et al., 2019). Person-to-person transmission has been well documented especially in health care workers and family members and may lead to large outbreaks with a significant impact on public health as observed in the Middle East and Korea (Ki, 2015; Mo and Fisher, 2016). People from any age can be infected with the virus, although the majority of cases have been observed in adults (Centers for Disease Control and Prevention, 2017). Clinical features range from asymptomatic or mild to severe disease and death (Zumla et al., 2015; Rabaan, 2017). Symptoms may include respiratory illness that can lead to acute respiratory distress syndrome (Assiri et al., 2013; Memish et al., 2013) and digestive symptoms including nausea, vomiting, and diarrhea (Centers for Disease Control and Prevention, 2017) with some patients developing renal failure (Bermingham et al., 2012; Jordan et al., 2018). The case fatality rate worldwide is $34.6 \%$, while in Saudi Arabia it is $37.5 \%$ (World Health Organization, 2019).

To date, there are no licensed vaccines or therapeutics for prevention or treatment of MERS-CoV infection and therapy is focused on supportive care to relive symptoms and in more severe cases to also support function of vital organs (Modjarrad, 2016; Mustafa et al., 2018). Since no specific treatment is available, supportive therapy and the use of broad-spectrum antivirals are currently the options for treatment (Rabaan et al., 2017). A broad range of therapeutics have been used in the clinic to treat MERS$\mathrm{CoV}$-infected patients, and their use is based on knowledge obtained during the severe acute respiratory syndrome (SARS) outbreak in 2003 and the recent influenza pandemic in 2009 (Mo and Fisher, 2016). Furthermore, comprehensive clinical studies are lacking and only field data are available (Dyall et al., 2017).

Therapies that have been used for treatment of patients infected with MERS-CoV include convalescent sera, corticosteroids, and/or antiviral therapeutics including interferons, ribavirin, and protease inhibitors (or combination of members from these groups)(Al-Tawfiq et al., 2014; Petersen et al., 2015; Zumla et al., 2016; Al-Tawfiq and Memish, 2017; Mustafa et al., 2018). There is a long list of potential therapeutics in preclinical phase that have shown promising results in vitro and in animal models. Comprehensive reviews of the current therapeutics 
under development have been published elsewhere (Zumla et al., 2016; Dyall et al., 2017; Rabaan et al., 2017).

\section{Convalescent Plasma}

The use of plasma obtained from recovering patients (convalescent plasma) has shown beneficial effects in outbreaks of SARS and influenza virus infections (Al-Tawfiq et al., 2017). Studies in these infections indicated that the use of $\mathrm{CP}$ can reduce viral loads and mortality (Mair-Jenkins et al., 2015; Wu et al., 2015). Due to the lack of clinical data demonstrating efficacy in MERS-CoV infection, the use of CP is considered an investigational treatment by the WHO (World Health Organization, 2014). Only two cases have been reported to use intravenous immunoglobulin as part of an integral treatment intervention; therefore, a beneficial effect was not readily quantifiable (Kapoor et al., 2014; Arabi et al., 2015). In preclinical studies, passive transfer of sera from MERS-CoV immune camels to infected mice reduced weight loss and lung histopathology (Zhao et al., 2015). A protocol to determine the safety and effectiveness of CP therapy for patients infected with MERS-CoV was recently published (Arabi et al., 2015). In this study, the authors concluded that due to the variation in the levels of MERS-CoV-specific immunoglobulins in recovered patients, a large screening will be necessary to obtain sufficient plasma donors. A clinical study was registered based on these findings, but since then, it has been withdrawn (NCT02190799). The use of CP remains as a potential therapeutic intervention but the lack of evidence to prove its safety and efficacy in treating infected patients limits its potential impact (Mustafa et al., 2018).

\section{Polyclonal Human Antibody Produced in Transchromosomic Cattle}

Transchromosomic cattle have been developed to produce fully human polyclonal IgG antibodies following immunization (Matsushita et al., 2014). Using this technology, polyclonal sera containing antibodies against the spike protein of MERS-CoV were produced (SAB-301) and demonstrated to be effective in neutralizing the virus in vitro and reducing lung virus titers in infected mice (Luke et al., 2016). A phase 1 randomized clinical trial aimed to evaluate the safety and tolerability of SAB-301 was conducted (NCT02788188). Results have been published and showed that the polyclonal human antibody is safe and well tolerated in patients at what could be considered therapeutic doses (Beigel et al., 2018).

\section{Monoclonal Antibodies Produced in Humanized Mice}

Using their VelocImmune mice, Regeneron produced fully human mAbs binding the spike protein of MERS-CoV. Two lead mAb candidates (REGN 3051 and REGN 3048) were further characterized in vitro and in vivo (Pascal et al., 2015). In vitro, both $\mathrm{mAbs}$ potently neutralized the MERS-CoV while in vivo studies in a mouse model of infection demonstrated that treatment of infected mice caused a reduction in lung virus titers and histopathology (Pascal et al., 2015). A phase 1 clinical trial to evaluate the safety, tolerability, pharmacokinetics (PK), and immunogenicity of single ascending doses of a combination of both mAbs administered IV in healthy adult volunteers is currently underway (NCT03301090).

\section{Broadly Acting Antivirals}

One of the main strategies implemented in the clinics for the treatment of MERS-CoV is the use of broadly acting antivirals although supportive therapy continues to be the primary approach for treatment (Modjarrad, 2016). Antivirals such as interferon and ribavirin that show strong inhibition of MERS-CoV in vitro have been used in the clinics with different degrees of success. Ribavirin is a synthetic guanosine nucleoside that interferes with the synthesis of viral mRNA. The best effect has been observed using a combination therapy of interferon (IFN) and ribavirin (Momattin et al., 2013). Different type I interferons including IFN- $\alpha 2 b$ and IFN- $\beta 1 b$ have been used in the management of patients with confirmed MERS-CoV infection (McIntosh, 2017). In a study using macaques, animals were treated with IFN- $a 2 b$ and ribavirin staring at $8 \mathrm{~h}$ after infection with MERS-CoV (Falzarano et al., 2013). The infected animals were euthanized at $72 \mathrm{~h}$ post-infection which is the peak of disease in this model. The group that received the combination treatment did not developed overt clinical signs of infection, had reduced levels of pro-inflammatory cytokines, reduction in lung virus titers, and reduction in overall lung pathology compared to the group of macaques that did not receive treatment. Most of the data on the efficacy of this combination therapy are from retrospectives studies (Mo and Fisher, 2016; McIntosh, 2017). In a study comparing infected patients that received this combination therapy in addition to support therapy, it was observed that these patients had a significantly better survival at day 14 post-laboratory confirmation of the infection (70\%) compared to the patients that only received the supportive therapy (29\%) (Omrani and Shalhoub, 2015). In a case study report of a health worker infected with MERS-CoV, the use of IFN- $\alpha 2 b$ plus ribavirin was associated with his recovery as well as with a beneficial prophylactic effect in his spouse who only developed a mild respiratory illness (Khalid et al., 2015). IFN- $\beta$ has also been used in combination therapies for the treatment of MERS-CoV infection (Shalhoub et al., 2015; Arabi et al., 2018). In a retrospective study that analyzed a small cohort of patients with laboratory-confirmed infection, it was observed that treatment with the combination of IFN- $\beta 1 \mathrm{a}$ and ribavirin did not significantly improve survival (Shalhoub et al., 2015). In a different retrospective study, analysis of the data demonstrated that administration of IFN- $\beta$ improved survival in treated patients. However, after a multivariate analysis, the positive effect was not significant (Al Ghamdi et al., 2016). Results vary between different retrospective studies and this is in part due to the presence of comorbidities and most importantly the time for treatment initiation (Al-Tawfiq and Memish, 2017), since it has been observed that the window of opportunity is very narrow and only effective when started within the first $48 \mathrm{~h}$ of confirmed diagnosis (Momattin et al., 2013; Al-Tawfiq et al., 2014; Widagdo et al., 2017). A case study of 
TABLE 1 | Novel therapeutics currently under development (clinical trials), for the treatment of influenza virus, respiratory syncytial virus (RSV), and Middle East respiratory syndrome coronavirus (MERS-CoV).

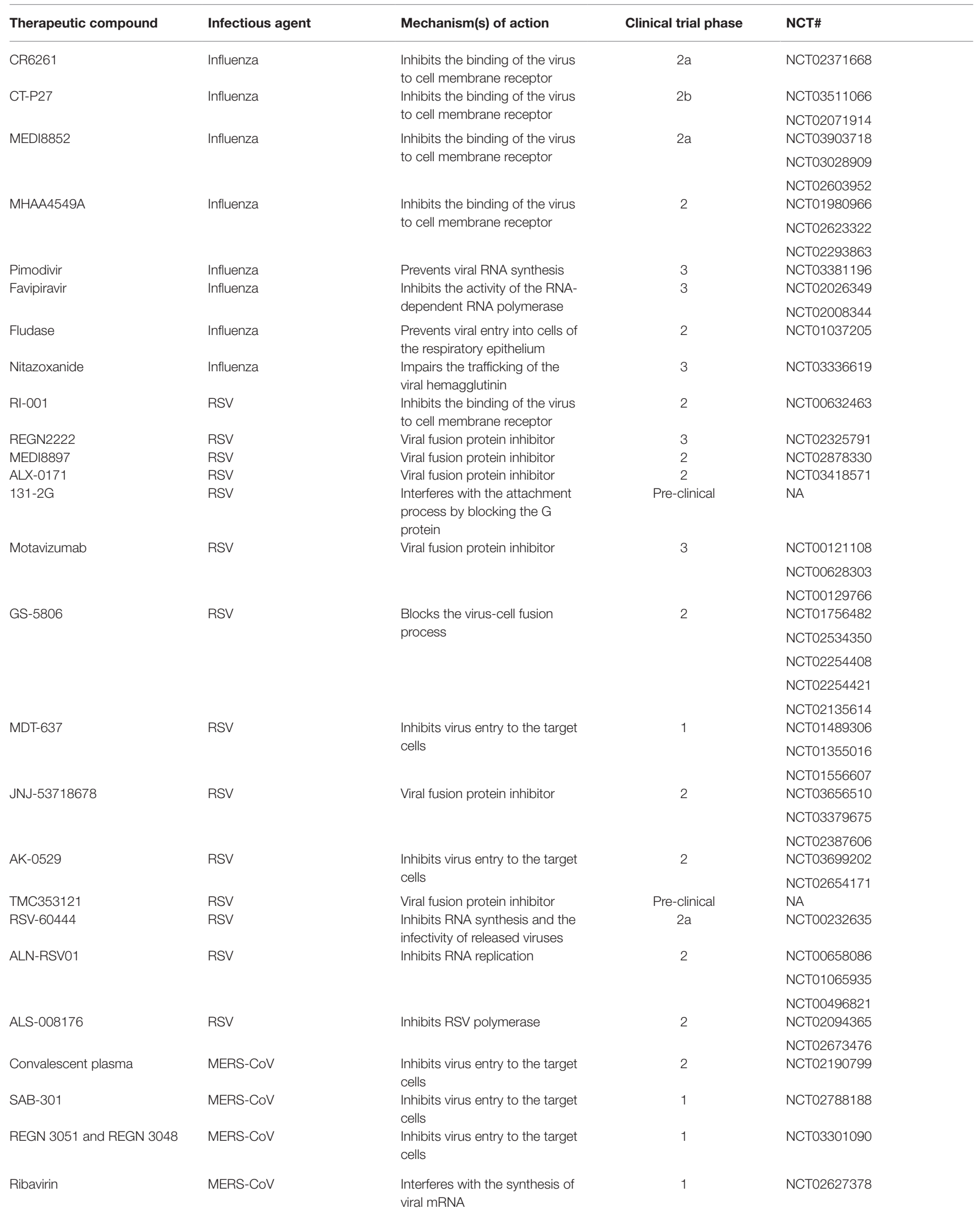


a MERS-CoV-infected patient who received ribavirin in combination with lopinavir/ritonavir $\left(\right.$ Kaletra $\left.^{\circledR}\right)$, a human immunodeficiency virus antiviral, and IFN- $\alpha 2 \mathrm{a}$, reported that this regimen was effective to treat the patient (Kim et al., 2016). The patient, a 64-year-old male with different comorbidities, started treatment on day 4 post admission and achieved viral clearance just 6 days after initiation of treatment and finally was discharged from the hospital on day 13 after admission (Kim et al., 2016). In a recent study, a combination of ribavirin and lopinavir/ritonavir was used as a post-exposure prophylaxis in health care workers who had been exposed to MERS-CoVinfected patients and demonstrated a reduction of $40 \%$ in the risk of infection (Park et al., 2019). A preclinical study in common marmosets infected with MERS-CoV showed that treatment with a combination of lopinavir/ritonavir and IFN- $\beta 1 \mathrm{~b}$ improved the clinical and pathological outcomes of the infected animals (Chan et al., 2015). A phase $2 / 3$ clinical trial NCT02845843 to determine the feasibility, efficacy, and safety of a combination therapy with lopinavir/ritonavir and IFN- $\beta 1 \mathrm{~b}$ for the treatment of MERS-CoV-infected patients was initiated in 2016. The clinical trial was expected to be concluded in July of 2018; however, no results or activity have been reported.

\section{CONCLUSIONS}

This review summarizes the current antivirals available for the treatment of influenza and RSV along with potential new therapies for these respiratory virus infections (Table 1). It also addresses the current therapies employing broad-spectrum antivirals for the treatment of MERS-CoV-infected patients (Table 1). Greater advances have been achieved in the field of influenza antivirals. Currently, three groups of drugs are

\section{REFERENCES}

Abarca, K., Jung, E., Fernández, P., Zhao, L., Harris, B., Connor, E. M., et al. (2009). Safety, tolerability, pharmacokinetics, and immunogenicity of motavizumab, a humanized, enhanced-potency monoclonal antibody for the prevention of respiratory syncytial virus infection in at-risk children. Pediatr. Infect. Dis. J. 28, 267-272. doi: 10.1097/INF.0b013e31818ffd03

Ackermann, M., Alnajjar, S., Larios-Mora, A., Koul, A., Rigaux, P., Gallup, J., et al. (2016). "Therapeutic efficacy of JNJ-53718678, a RSV fusion inhibitor, in neonatal lambs" in 10th international respiratory syncytial virus symposium (Argentina: Patagonia).

Al Ghamdi, M., Alghamdi, K. M., Ghandoora, Y., Alzahrani, A., Salah, F., Alsulami, A., et al. (2016). Treatment outcomes for patients with middle eastern respiratory syndrome coronavirus (MERS CoV) infection at a coronavirus referral center in the Kingdom of Saudi Arabia. BMC Infect. Dis. 16:174. doi: 10.1186/s12879-016-1492-4

Alame, M. M., Massaad, E., and Zaraket, H. (2016). Peramivir: a novel intravenous neuraminidase inhibitor for treatment of acute influenza infections. Front. Microbiol. 7:450. doi: 10.3389/fmicb.2016.00450

Ali, S. O., Takas, T., Nyborg, A., Shoemaker, K., Kallewaard, N. L., Chiong, R., et al. (2018). Evaluation of MEDI8852, an anti-influenza A monoclonal antibody, in treating acute uncomplicated influenza. Antimicrob. Agents Chemother. 62:e0694-18. doi: 10.1128/AAC.00694-18

Al-Tawfiq, J. A., Alfaraj, S. H., Altuwaijri, T. A., and Memish, Z. A. (2017). A cohort-study of patients suspected for MERS-CoV in a referral hospital in Saudi Arabia. J. Infect. 75, 378-379. doi: 10.1016/j.jinf.2017.06.002 approved for the treatment of influenza, including the newly approved viral polymerase inhibitor baloxavir marboxil and only one approved for RSV, the polyclonal palivizumab. Although effective, these drugs have limitations such as a reduced window of opportunity, potential to produce drug-resistant viruses, and high cost (Palivizumab). This highlights the need for more and better antiviral drugs to treat these respiratory infections. MERS-CoV recently emerged as a zoonotic respiratory infection and, therefore, no effective antivirals are approved for treatment. The initial approach has been to follow examples of antiviral therapies used during the recent SARS outbreak; however, as described in this review, the approach using broad-spectrum antivirals has not been very successful.

Great advances have been made in the last few years and several antivirals are currently under development and many have reached early stages in clinical trials. This is a very exciting and evolving field that will continue producing more effective antivirals that are highly needed for the treatment of respiratory viral infections of global public health concern.

\section{AUTHOR CONTRIBUTIONS}

$\mathrm{MB}$ and VL-G wrote, reviewed, and approved the submitted manuscript.

\section{FUNDING}

This work was supported in part by the NIAID-funded Center of Excellence for Influenza Research and Surveillance-CEIRS (Contract HHSN272201400008C).

Al-Tawfiq, J. A., and Memish, Z. A. (2017). Update on therapeutic options for Middle East respiratory syndrome coronavirus (MERS-CoV). Expert Rev. Anti-Infect. Ther. 15, 269-275. doi: 10.1080/14787210.2017.1271712

Al-Tawfiq, J. A., Momattin, H., Dib, J., and Memish, Z. A. (2014). Ribavirin and interferon therapy in patients infected with the Middle East respiratory syndrome coronavirus: an observational study. Int. J. Infect. Dis. 20, 42-46. doi: $10.1016 /$ j.ijid.2013.12.003

Amarelle, L., Lecuona, E., and Sznajder, J. I. (2017). Anti-influenza treatment: drugs currently used and under development. Arch. Bronconeumol. 53, 19-26. doi: 10.1016/j.arbres.2016.07.004

Antonini, T. M., Coilly, A., Rossignol, E., Fougerou-Leurent, C., Dumortier, J., Leroy, V., et al. (2018). Sofosbuvir-based regimens in HIV/HCV Coinfected patients after liver transplantation: results from the ANRS CO23 CUPILT study. Transplantation 102, 119-126. doi: 10.1097/TP.0000000000001928

Arabi, Y. M., Alothman, A., Balkhy, H. H., Al-Dawood, A., Aljohani, S., Al Harbi, S., et al. (2018). Treatment of Middle East respiratory syndrome with a combination of lopinavir-ritonavir and interferon-betalb (MIRACLE trial): study protocol for a randomized controlled trial. Trials 19:81. doi: 10.1186/s13063-017-2427-0

Arabi, Y., Balkhy, H., Hajeer, A. H., Bouchama, A., Hayden, F. G., Al-Omari, A., et al. (2015). Feasibility, safety, clinical, and laboratory effects of convalescent plasma therapy for patients with Middle East respiratory syndrome coronavirus infection: a study protocol. Springerplus 4:709. doi: 10.1186/s40064-015-1490-9

Assiri, A., Al-Tawfiq, J. A., Al-Rabeeah, A. A., Al-Rabiah, F. A., Al-Hajjar, S., Al-Barrak, A., et al. (2013). Epidemiological, demographic, and clinical characteristics of 47 cases of Middle East respiratory syndrome coronavirus disease from Saudi Arabia: a descriptive study. Lancet Infect. Dis. 13, 752-761. doi: 10.1016/S1473-3099(13)70204-4 
Battles, M. B., Langedijk, J. P., Furmanova-Hollenstein, P., Chaiwatpongsakorn, S., Costello, H. M., Kwanten, L., et al. (2016). Molecular mechanism of respiratory syncytial virus fusion inhibitors. Nat. Chem. Biol. 12, 87-93. doi: 10.1038/ nchembio. 1982

Beigel, J. H., Voell, J., Kumar, P., Raviprakash, K., Wu, H., Jiao, J. A., et al. (2018). Safety and tolerability of a novel, polyclonal human anti-MERS coronavirus antibody produced from transchromosomic cattle: a phase 1 randomised, double-blind, single-dose-escalation study. Lancet Infect. Dis. 18, 410-418. doi: 10.1016/S1473-3099(18)30002-1

Belardo, G., Cenciarelli, O., La Frazia, S., Rossignol, J. F., and Santoro, M. G. (2015). Synergistic effect of nitazoxanide with neuraminidase inhibitors against influenza A viruses in vitro. Antimicrob. Agents Chemother. 59, 1061-1069. doi: 10.1128/AAC.03947-14

Belser, J. A., Lu, X., Szretter, K. J., Jin, X., Aschenbrenner, L. M., Lee, A., et al. (2007). DAS181, a novel sialidase fusion protein, protects mice from lethal avian influenza H5N1 virus infection. J. Infect. Dis. 196, 1493-1499. doi: $10.1086 / 522609$

Bermingham, A., Chand, M. A., Brown, C. S., Aarons, E., Tong, C., Langrish, C., et al. (2012). Severe respiratory illness caused by a novel coronavirus, in a patient transferred to the United Kingdom from the Middle East, September 2012. Euro Surveill. 17:20290. doi: 10.2807/ese.17.40.20290-en

Bonavia, A., Franti, M., Keaney, E. P., Kuhen, K., Seepersaud, M., Radetich, B., et al. (2011). Identification of broad-spectrum antiviral compounds and assessment of the druggability of their target for efficacy against respiratory syncytial virus (RSV). Proc. Natl. Acad. Sci. USA 108, 6739-6744. doi: 10.1073/pnas.1017142108

Bonfanti, J.-F., Doublet, F., Fortin, J., Lacrampe, J., Guillemont, J., Muller, P., et al. (2007). Selection of a respiratory syncytial virus fusion inhibitor clinical candidate, part 1: improving the pharmacokinetic profile using the structure-property relationship. J. Med. Chem. 50, 4572-4584. doi: 10.1021/ jm070143x

Bonfanti, J.-F., Meyer, C., Doublet, F., Fortin, J., Muller, P., Queguiner, L., et al. (2008). Selection of a respiratory syncytial virus fusion inhibitor clinical candidate. 2. Discovery of a morpholinopropylaminobenzimidazole derivative (TMC353121). J. Med. Chem. 51, 875-896. doi: 10.1021/jm701284j

Borchardt, R. A., and Rolston, K. V. (2012). Respiratory tract infections: emerging viral pathogens. JAAPA 25, 19-20.

Boyd, M. J., Bandarage, U. K., Bennett, H., Byrn, R. R., Davies, I., Gu, W., et al. (2015). Isosteric replacements of the carboxylic acid of drug candidate VX-787: effect of charge on antiviral potency and kinase activity of azaindolebased influenza PB2 inhibitors. Bioorg. Med. Chem. Lett. 25, 1990-1994. doi: 10.1016/j.bmcl.2015.03.013

Byrn, R. A., Jones, S. M., Bennett, H. B., Bral, C., Clark, M. P., Jacobs, M. D., et al. (2015). Preclinical activity of VX-787, a first-in-class, orally bioavailable inhibitor of the influenza virus polymerase PB2 subunit. Antimicrob. Agents Chemother. 59, 1569-1582. doi: 10.1128/AAC.04623-14

Centers for Disease Control and Prevention. (2017). Middle East respiratory syndrome (MERS). Available at: https://www.cdc.gov/coronavirus/mers/index. html (Accessed April 17, 2019).

Centers for Disease Control and Prevention. (2018a). Influenza antiviral medications: summary for clinicians. Available at: https://www. cdc.gov/flu/professionals/antivirals/summary-clinicians.htm (Accessed April 17, 2019).

Centers for Disease Control and Prevention. (2018b). Respiratory syncytial virus (RSV). Available at: https://www.cdc.gov/rsv/clinical/index.html (Accessed June 2016, 2019).

Centers for Disease Control and Prevention. (2018c). Summary of the 107-2018 Influenza season. Available at: https://www.cdc.gov/flu/about/season/fluseason-2017-2018.htm (Accessed April 17, 2019).

Challa, S., Scott, A. D., Yuzhakov, O., Zhou, Y., Tiong-Yip, C. L., Gao, N., et al. (2015). Mechanism of action for respiratory syncytial virus inhibitor RSV604. Antimicrob. Agents Chemother. 59, 1080-1087. doi: 10.1128/ AAC.04119-14

Chan, S. M., Damdinjav, B., Perera, R. A., Chu, D. K., Khishgee, B., Enkhbold, B., et al. (2015). Absence of MERS-coronavirus in Bactrian camels, southern Mongolia, November 2014. Emerg. Infect. Dis. 21, 1269-1271. doi: 10.3201/ eid2107.150178

Chapman, J., Abbott, E., Alber, D. G., Baxter, R. C., Bithell, S. K., Henderson, E. A., et al. (2007). RSV604, a novel inhibitor of respiratory syncytial virus replication. Antimicrob. Agents Chemother. 51, 3346-3353. doi: 10.1128/ AAC.00211-07

Chaudhuri, S., Symons, J. A., and Deval, J. (2018). Innovation and trends in the development and approval of antiviral medicines: 1987-2017 and beyond Antiviral Res. 155, 76-88. doi: 10.1016/j.antiviral.2018.05.005

Clark, M. P., Ledeboer, M. W., Davies, I., Byrn, R. A., Jones, S. M., Perola, E., et al. (2014). Discovery of a novel, first-in-class, orally bioavailable azaindole inhibitor (VX-787) of influenza PB2. J. Med. Chem. 57, 6668-6678. doi: $10.1021 / j m 5007275$

Collins, P. L., Fearns, R., and Graham, B. S. (2013). "Respiratory syncytial virus: virology, reverse genetics, and pathogenesis of disease" in Challenges and opportunities for respiratory syncytial virus vaccines. eds. L. J. Anderson and S. B. Graham (Berlin, Heidelberg: Springer-Verlag), 3-38.

Davidson, S. (2018). Treating influenza infection, from now and into the future. Front. Immunol. 9:1946. doi: 10.3389/fimmu.2018.01946

Deng, R., Lee, A. P., Maia, M., Lim, J. J., Burgess, T., Horn, P., et al. (2018). Pharmacokinetics of MHAA4549A, an anti-influenza A monoclonal antibody, in healthy subjects challenged with influenza A virus in a phase IIa randomized trial. Clin. Pharmacokinet. 57, 367-377. doi: 10.1007/s40262-017-0564-y

Detalle, L., Larios, A., Gallup, L., Van Geelen, A., Duprez, L., and Stohr, T. (2014). "Delivery of ALX-0171 by inhalation greatly reduces disease burden in a neonatal lamb RSV infection model" in 9th international respiratory syncytial virus symposium (Cape Town, South Africa) Abstract OP 72.

Detalle, L., Stohr, T., Palomo, C., Piedra, P. A., Gilbert, B. E., Mas, V., et al. (2016). Generation and characterization of ALX-0171, a potent novel therapeutic nanobody for the treatment of respiratory syncytial virus infection. Antimicrob. Agents Chemother. 60, 6-13. doi: 10.1128/AAC.01802-15

Deval, J., Hong, J., Wang, G., Taylor, J., Smith, L. K., Fung, A., et al. (2015). Molecular basis for the selective inhibition of respiratory syncytial virus RNA polymerase by 2 -fluoro- 4 -chloromethyl-cytidine triphosphate. PLoS Pathog. 11:e1004995. doi: 10.1371/journal.ppat.1004995

Devincenzo, J. P. (2000). Therapy of respiratory syncytial virus infection. Pediatr. Infect. Dis. J. 19, 786-790. doi: 10.1097/00006454-200008000-00032

Devincenzo, J., Lambkin-Williams, R., Wilkinson, T., Cehelsky, J., Nochur, S., Walsh, E., et al. (2010). A randomized, double-blind, placebo-controlled study of an RNAi-based therapy directed against respiratory syncytial virus. Proc. Natl. Acad. Sci. USA 107, 8800-8805. doi: 10.1073/pnas.0912186107

Devincenzo, J. P., Mcclure, M. W., Symons, J. A., Fathi, H., Westland, C., Chanda, S., et al. (2015). Activity of oral ALS-008176 in a respiratory syncytial virus challenge study. N. Engl. J. Med. 373, 2048-2058. doi: 10.1056/ NEJMoa1413275

Domachowske, J. B., Khan, A. A., Esser, M. T., Jensen, K., Takas, T., Villafana, T., et al. (2018). Safety, tolerability, and pharmacokinetics of MEDI8897, an extended half-life single-dose respiratory syncytial virus prefusion F-targeting monoclonal antibody administered as a single dose to healthy preterm infants. Pediatr. Infect. Dis. J. 37, 886-892. doi: 10.1097/INF.0000000000001916

Dyall, J., Gross, R., Kindrachuk, J., Johnson, R. F., Olinger, G. G. Jr., Hensley, L. E., et al. (2017). Middle East respiratory syndrome and severe acute respiratory syndrome: current therapeutic options and potential targets for novel therapies. Drugs 77, 1935-1966. doi: 10.1007/s40265-017-0830-1

Ekiert, D. C., Friesen, R. H., Bhabha, G., Kwaks, T., Jongeneelen, M., Yu, W., et al. (2011). A highly conserved neutralizing epitope on group 2 influenza A viruses. Science 333, 843-850. doi: 10.1126/science.1204839

Enjuanes, L., Zuniga, S., Castano-Rodriguez, C., Gutierrez-Alvarez, J., Canton, J., and Sola, I. (2016). Molecular basis of coronavirus virulence and vaccine development. Adv. Virus Res. 96, 245-286. doi: 10.1016/bs.aivir.2016.08.003

Erbelding, E. J., Post, D. J., Stemmy, E. J., Roberts, P. C., Augustine, A. D., Ferguson, S., et al. (2018). A universal influenza vaccine: the strategic plan for the National Institute of Allergy and Infectious Diseases. J. Infect. Dis. 218, 347-354. doi: 10.1093/infdis/jiy103

Falzarano, D., De Wit, E., Rasmussen, A. L., Feldmann, F., Okumura, A., Scott, D. P., et al. (2013). Treatment with interferon-alpha2b and ribavirin improves outcome in MERS-CoV-infected rhesus macaques. Nat. Med. 19, 1313-1317. doi: $10.1038 / \mathrm{nm} .3362$

Ferkol, T., and Schraufnagel, D. (2014). The global burden of respiratory disease. Ann. Am. Thorac. Soc. 11, 404-406. doi: 10.1513/AnnalsATS.201311-405PS

Food and Drug Administration. (2018). FDA approves new drug to treat influenza. Available at: https://www.fda.gov/NewsEvents/Newsroom/ PressAnnouncements/ucm624226.htm (Accessed October 24, 2018). 
Friesen, R. H., Koudstaal, W., Koldijk, M. H., Weverling, G. J., Brakenhoff, J. P., Lenting, P. J., et al. (2010). New class of monoclonal antibodies against severe influenza: prophylactic and therapeutic efficacy in ferrets. PLoS One 5:e9106. doi: 10.1371/journal.pone.0009106

Frogel, M., Nerwen, C., Cohen, A., Vanveldhuisen, P., Harrington, M., and Boron, M. (2008). Prevention of hospitalization due to respiratory syncytial virus: results from the palivizumab outcomes registry. J. Perinatol. 28, 511-517. doi: 10.1038/jp.2008.28

Fukao, K., Noshi, T., Yamamoto, A., Kitano, M., Ando, Y., Noda, T., et al. (2018). Combination treatment with the cap-dependent endonuclease inhibitor baloxavir marboxil and a neuraminidase inhibitor in a mouse model of influenza A virus infection. J. Antimicrob. Chemother. 74, 654-662. doi: $10.1093 / \mathrm{jac} / \mathrm{dky} 462$

Furuta, Y., Komeno, T., and Nakamura, T. (2017). Favipiravir (T-705), a broad spectrum inhibitor of viral RNA polymerase. Proc. Jpn. Acad. Ser. B Phys. Biol. Sci. 93, 449-463. doi: 10.2183/pjab.93.027

Furuta, Y., Takahashi, K., Kuno-Maekawa, M., Sangawa, H., Uehara, S., Kozaki, K., et al. (2005). Mechanism of action of T-705 against influenza virus. Antimicrob. Agents Chemother. 49, 981-986. doi: 10.1128/AAC.49.3.981-986.2005

Gottlieb, J., Zamora, M. R., Hodges, T., Musk, A., Sommerwerk, U., Dilling, D., et al. (2016). ALN-RSV01 for prevention of bronchiolitis obliterans syndrome after respiratory syncytial virus infection in lung transplant recipients. J. Heart Lung Transplant. 35, 213-221. doi: 10.1016/j. healun.2015.08.012

Griffin, M. P., Khan, A. A., Esser, M. T., Jensen, K., Takas, T., Kankam, M. K., et al. (2017). Safety, tolerability, and pharmacokinetics of MEDI8897, the respiratory syncytial virus prefusion F-targeting monoclonal antibody with an extended half-life, in healthy adults. Antimicrob. Agents Chemother. 61, e01714-e01716. doi: 10.1128/AAC.01714-16

Griffiths, C., Drews, S. J., and Marchant, D. J. (2017). Respiratory syncytial virus: infection, detection, and new options for prevention and treatment. Clin. Microbiol. Rev. 30, 277-319. doi: 10.1128/CMR.00010-16

Gurnett-Bander, A., Perez-Caballero, D., Sivapalasingam, S., Duan, X., and Macdonald, D. (2016). Human antibodies to respiratory syncytial virus F protein and methods of use thereof. Google Patents.

Haffizulla, J., Hartman, A., Hoppers, M., Resnick, H., Samudrala, S., Ginocchio, C., et al. (2014). Effect of nitazoxanide in adults and adolescents with acute uncomplicated influenza: a double-blind, randomised, placebo-controlled, phase 2b/3 trial. Lancet Infect. Dis. 14, 609-618. doi: 10.1016/ S1473-3099(14)70717-0

Hanfelt-Goade, D., Maimon, N., Nimer, A., Riviere, F., Catherinot, E., Ison, M., et al. (2018). "A phase 2b, randomized, double-blind, placebo-controlled trial of Presatovir (GS-5806), a novel Oral RSV fusion inhibitor, for the treatment of respiratory syncytial virus (RSV) in hospitalized adults" in C17. New insights in acute pulmonary infections (San Diego, CA: American Thoracic Society), A4457-A4457.

Hanton, G., Detalle, L., Priem, S., Bouche, M.-P., Depla, E., and Baumeister, J. (2012). ALX-0171 toxicity study in RSV-infected cotton rats: safety and therapeutic potential. Toxicol. Lett. 211:S43. doi: 10.1016/j. toxlet.2012.03.176

Hayden, F. G., Sugaya, N., Hirotsu, N., Lee, N., De Jong, M. D., Hurt, A. C., et al. (2018). Baloxavir Marboxil for uncomplicated influenza in adults and adolescents. N. Engl. J. Med. 379, 913-923. doi: 10.1056/NEJMoa1716197

Haynes, L. M., Caidi, H., Radu, G. U., Miao, C., Harcourt, J. L., Tripp, R. A., et al. (2009). Therapeutic monoclonal antibody treatment targeting respiratory syncytial virus (RSV) G protein mediates viral clearance and reduces the pathogenesis of RSV infection in BALB/c mice. J. Infect. Dis. 200, 439-447. doi: $10.1086 / 600108$

Heylen, E., Neyts, J., and Jochmans, D. (2017). Drug candidates and model systems in respiratory syncytial virus antiviral drug discovery. Biochem. Pharmacol. 127, 1-12. doi: 10.1016/j.bcp.2016.09.014

Hotard, A. L., Lee, S., Currier, M. G., Crowe, J. E., Sakamoto, K., Newcomb, D. C., et al. (2015). Identification of residues in the human respiratory syncytial virus fusion protein that modulate fusion activity and pathogenesis. J. Virol. 89, 512-522. doi: 10.1128/JVI.02472-14

Huntjens, D. R., Ouwerkerk-Mahadevan, S., Brochot, A., Rusch, S., Stevens, M., and Verloes, R. (2017). Population pharmacokinetic modeling of JNJ-53718678, a novel fusion inhibitor for the treatment of respiratory syncytial virus: results from a phase I, double-blind, randomized, placebo-controlled first- in-human study in healthy adult subjects. Clin. Pharmacokinet. 56, 1331-1342. doi: $10.1007 / s 40262-017-0522-8$

International Society for Influenza and other Respiratory Viral Diseases (2018). Prevention and treatment of respiratory viral infections: presentations on antiviral, traditional therapies and host-directed interventions at the 5th ISIRV antiviral group conference. Meeting report. Antiviral Res. 149, 118-142. doi: 10.1016/j.antiviral.2017.11.013

Ison, M. G. (2017). Antiviral treatments. Clin. Chest Med. 38, 139-153. doi: 10.1016/j.ccm.2016.11.008

Ispas, G., Koul, A., Verbeeck, J., Sheehan, J., Sanders-Beer, B., Roymans, D., et al. (2015). Antiviral activity of TMC353121, a respiratory syncytial virus (RSV) fusion inhibitor, in a non-human primate model. PLoS One 10:e126959. doi: 10.1371/journal.pone.0126959

Israel, S., Rusch, S., Devincenzo, J., Boyers, A., Fok-Seang, J., Huntjens, D., et al. (2016). "Effect of oral JNJ-53718678 (JNJ-678) on disease severity in healthy adult volunteers experimentally inoculated with live respiratory syncytial virus (RSV): a placebo-controlled challenge study" in Open forum infectious diseases (New Orleans, LA: Oxford University Press).

Jin, Y., Lei, C., Hu, D., Dimitrov, D. S., and Ying, T. (2017). Human monoclonal antibodies as candidate therapeutics against emerging viruses. Front. Med. 11, 462-470. doi: 10.1007/s11684-017-0596-6

Johnson, S. M., McNally, B. A., Ioannidis, I., Flano, E., Teng, M. N., Oomens, A. G., et al. (2015). Respiratory syncytial virus uses CX3CR1 as a receptor on primary human airway epithelial cultures. PLoS Pathog. 11:e1005318. doi: 10.1371/journal.ppat.1005318

Jones, J. C., Kumar, G., Barman, S., Najera, I., White, S. W., Webby, R. J., et al. (2018). Identification of the I38T PA substitution as a resistance marker for next-generation influenza virus endonuclease inhibitors. MBio 9:e00430-18. doi: $10.1128 / \mathrm{mBio} .01868-18$

Jordan, P. C., Stevens, S. K., and Deval, J. (2018). Nucleosides for the treatment of respiratory RNA virus infections. Antivir. Chem. Chemother. 26:2040206618764483. doi: 10.1177/2040206618764483

Jorquera, P. A., and Tripp, R. A. (2017). Respiratory syncytial virus: prospects for new and emerging therapeutics. Expert Rev. Respir. Med. 11, 609-615. doi: 10.1080/17476348.2017.1338567

Kallewaard, N. L., Corti, D., Collins, P. J., Neu, U., McAuliffe, J. M., Benjamin, E., et al. (2016). Structure and function analysis of an antibody recognizing all influenza A subtypes. Cell 166, 596-608. doi: 10.1016/j.cell.2016.05.073

Kapoor, M., Pringle, K., Kumar, A., Dearth, S., Liu, L., Lovchik, J., et al. (2014). Clinical and laboratory findings of the first imported case of Middle East respiratory syndrome coronavirus to the United States. Clin. Infect. Dis. 59, 1511-1518. doi: 10.1093/cid/ciu635

Khalid, M., Al Rabiah, F., Khan, B., Al Mobeireek, A., Butt, T. S., and Al Mutairy, E. (2015). Ribavirin and interferon-alpha2b as primary and preventive treatment for Middle East respiratory syndrome coronavirus: a preliminary report of two cases. Antivir. Ther. 20, 87-91. doi: 10.3851/IMP2792

Ki, M. (2015). 2015 MERS outbreak in Korea: hospital-to-hospital transmission. Epidemiol. Health 37:e2015033. doi: 10.4178/epih/e2015033

Kim, Y. I., Pareek, R., Murphy, R., Harrison, L., Farrell, E., Cook, R., et al. (2017). The antiviral effects of RSV fusion inhibitor, MDT-637, on clinical isolates, vs its achievable concentrations in the human respiratory tract and comparison to ribavirin. Influenza Other Respir. Viruses 11, 525-530. doi: 10.1111/irv.12503

Kim, J., Seong, R.-K., Kumar, M., and Shin, O. S. (2018). Favipiravir and ribavirin inhibit replication of Asian and African strains of Zika virus in different cell models. Viruses 10:72. doi: 10.3390/v10020072

Kim, U. J., Won, E. J., Kee, S. J., Jung, S. I., and Jang, H. C. (2016). Combination therapy with lopinavir/ritonavir, ribavirin and interferon-alpha for Middle East respiratory syndrome. Antivir. Ther. 21, 455-459. doi: 10.3851/IMP3002

Koszalka, P., Tilmanis, D., and Hurt, A. C. (2017). Influenza antivirals currently in late-phase clinical trial. Influenza Other Respir. Viruses 11, 240-246. doi: 10.1111/irv.12446

Koudstaal, W., Koldijk, M. H., Brakenhoff, J. P., Cornelissen, L. A., Weverling, G. J., Friesen, R. H., et al. (2009). Pre- and postexposure use of human monoclonal antibody against $\mathrm{H} 5 \mathrm{~N} 1$ and $\mathrm{H} 1 \mathrm{~N} 1$ influenza virus in mice: viable alternative to oseltamivir. J. Infect. Dis. 200, 1870-1873. doi: $10.1086 / 648378$

Lim, J. J., Deng, R., Derby, M. A., Larouche, R., Horn, P., Anderson, M., et al. (2016). Two phase 1, randomized, double-blind, placebo-controlled, single- 
ascending-dose studies to investigate the safety, tolerability, and pharmacokinetics of an anti-influenza A virus monoclonal antibody, MHAA4549A, in healthy volunteers. Antimicrob. Agents Chemother. 60, 5437-5444. doi: 10.1128/AAC.00607-16

Lu, P. Y., Evans, D. M., Xu, J. J., Lu, A. Y., and Ge, Q. (2018). Compositions and methods for "resistance-proof" SiRNA therapeutics for influenza. Google Patents.

Luke, T., Wu, H., Zhao, J., Channappanavar, R., Coleman, C. M., Jiao, J. A., et al. (2016). Human polyclonal immunoglobulin G from transchromosomic bovines inhibits MERS-CoV in vivo. Sci. Transl. Med. 8:326ra321. doi: 10.1126/scitranslmed.aaf1061

Mackman, R. L., Sangi, M., Sperandio, D., Parrish, J. P., Eisenberg, E., Perron, M., et al. (2015). Discovery of an oral respiratory syncytial virus (RSV) fusion inhibitor (GS-5806) and clinical proof of concept in a human RSV challenge study. J. Med. Chem. 58, 1630-1643. doi: 10.1021/jm5017768

Mair-Jenkins, J., Saavedra-Campos, M., Baillie, J. K., Cleary, P., Khaw, F. M., Lim, W. S., et al. (2015). The effectiveness of convalescent plasma and hyperimmune immunoglobulin for the treatment of severe acute respiratory infections of viral etiology: a systematic review and exploratory meta-analysis. J. Infect. Dis. 211, 80-90. doi: 10.1093/infdis/jiu396

Malakhov, M. P., Aschenbrenner, L. M., Smee, D. F., Wandersee, M. K., Sidwell, R. W., Gubareva, L. V., et al. (2006). Sialidase fusion protein as a novel broad-spectrum inhibitor of influenza virus infection. Antimicrob. Agents Chemother. 50, 1470-1479. doi: 10.1128/AAC.50.4.1470-1479.2006

Marjuki, H., Mishin, V. P., Chesnokov, A. P., De La Cruz, J. A., Fry, A. M., Villanueva, J., et al. (2014). An investigational antiviral drug, DAS181, effectively inhibits replication of zoonotic influenza A virus subtype H7N9 and protects mice from lethality. J. Infect. Dis. 210, 435-440. doi: 10.1093/ infdis/jiu105

Marjuki, H., Mishin, V. P., Chesnokov, A. P., Jones, J., De La Cruz, J. A., Sleeman, K., et al. (2015). Characterization of drug-resistant influenza A(H7N9) variants isolated from an oseltamivir-treated patient in Taiwan. J. Infect. Dis. 211, 249-257. doi: 10.1093/infdis/jiu447

Marty, F., Chemaly, R., Liakopoulou, E., Dent, J., and Powell, K. (2007). "A double-blind, randomized, placebo-controlled study to evaluate the safety and efficacy of RSV604 in adults with respiratory syncytial virus infection following stem cell transplantation" in Proceedings of the IXth international symposium on respiratory viral infections. International Society for Influenza and other Respiratory Virus Diseases (ISIRV).

Matsushita, H., Sano, A., Wu, H., Jiao, J. A., Kasinathan, P., Sullivan, E. J., et al. (2014). Triple immunoglobulin gene knockout transchromosomic cattle: bovine lambda cluster deletion and its effect on fully human polyclonal antibody production. PLoS One 9:e90383. doi: 10.1371/journal.pone.0090383

McBride, J. M., Lim, J. J., Burgess, T., Deng, R., Derby, M. A., Maia, M., et al. (2017). Phase 2 randomized trial of the safety and efficacy of MHAA4549A, a broadly neutralizing monoclonal antibody, in a human influenza A virus challenge model. Antimicrob. Agents Chemother. 61:e01154-17. doi: 10.1128/ AAC.01154-17

McIntosh, K. (2017). Middle east respiratory syndrome coronavirus: Treatment and prevention.

Memish, Z. A., Zumla, A. I., and Assiri, A. (2013). Middle East respiratory syndrome coronavirus infections in health care workers. N. Engl. J. Med. 369, 884-886. doi: 10.1056/NEJMc1308698

Mo, Y., and Fisher, D. (2016). A review of treatment modalities for Middle East respiratory syndrome. J. Antimicrob. Chemother. 71, 3340-3350. doi: 10.1093/jac/dkw338

Modjarrad, K. (2016). Treatment strategies for Middle East respiratory syndrome coronavirus. J. Virus Erad. 2, 1-4.

Momattin, H., Mohammed, K., Zumla, A., Memish, Z. A., and Al-Tawfiq, J. A. (2013). Therapeutic options for Middle East respiratory syndrome coronavirus (MERS-CoV) - possible lessons from a systematic review of SARS-CoV therapy. Int. J. Infect. Dis. 17, e792-e798. doi: 10.1016/j.ijid.2013.07.002

Morris, J., Blount, R. Jr., and Savage, R. (1956). Recovery of cytopathogenic agent from chimpanzees with goryza. Proc. Soc. Exp. Biol. Med. 92, 544-549.

Moss, R. B., Hansen, C., Sanders, R. L., Hawley, S., Li, T., and Steigbigel, R. T. (2012). A phase II study of DAS181, a novel host directed antiviral for the treatment of influenza infection. J. Infect. Dis. 206, 1844-1851. doi: 10.1093/infdis/jis622
Mustafa, S., Balkhy, H., and Gabere, M. N. (2018). Current treatment options and the role of peptides as potential therapeutic components for Middle East respiratory syndrome (MERS): a review. J. Infect. Public Health 11, 9-17. doi: 10.1016/j.jiph.2017.08.009

Nakamura, G., Chai, N., Park, S., Chiang, N., Lin, Z., Chiu, H., et al. (2013). An in vivo human-plasmablast enrichment technique allows rapid identification of therapeutic influenza A antibodies. Cell Host Microbe 14, 93-103. doi: 10.1016/j.chom.2013.06.004

Noshi, T., Kitano, M., Taniguchi, K., Yamamoto, A., Omoto, S., Baba, K., et al. (2018). In vitro characterization of baloxavir acid, a first-in-class cap-dependent endonuclease inhibitor of the influenza virus polymerase PA subunit. Antiviral Res. 160, 109-117. doi: 10.1016/j.antiviral.2018.10.008

O’brien, K. L., Chandran, A., Weatherholtz, R., Jafri, H. S., Griffin, M. P., Bellamy, T., et al. (2015). Efficacy of motavizumab for the prevention of respiratory syncytial virus disease in healthy native American infants: a phase 3 randomised double-blind placebo-controlled trial. Lancet Infect. Dis. 15, 1398-1408. doi: 10.1016/S1473-3099(15)00247-9

Omrani, A. S., and Shalhoub, S. (2015). Middle East respiratory syndrome coronavirus (MERS-CoV): what lessons can we learn? J. Hosp. Infect. 91, 188-196. doi: 10.1016/j.jhin.2015.08.002

Ormond, L., Liu, P., Matuszewski, S., Renzette, N., Bank, C., Zeldovich, K., et al. (2017). The combined effect of oseltamivir and favipiravir on influenza A virus evolution. Genome Biol. Evol. 9, 1913-1924. doi: 10.1093/gbe/evx138

Paden, C. R., Yusof, M., Al Hammadi, Z. M., Queen, K., Tao, Y., Eltahir, Y. M., et al. (2018). Zoonotic origin and transmission of Middle East respiratory syndrome coronavirus in the UAE. Zoonoses Public Health 65, 322-333. doi: $10.1111 /$ zph.12435

Palese, P., Bodo, G., and Tuppy, H. (1970). Quantitative determination of neuraminidase-active foci in cell monolayer cultures infected with influenza or Newcastle disease virus. J. Virol. 6, 556-558.

Park, S. Y., Lee, J. S., Son, J. S., Ko, J. H., Peck, K. R., Jung, Y., et al. (2019). Post-exposure prophylaxis for Middle East respiratory syndrome in healthcare workers. J. Hosp. Infect. 101, 42-46. doi: 10.1016/j.jhin.2018.09.005

Pascal, K. E., Coleman, C. M., Mujica, A. O., Kamat, V., Badithe, A., Fairhurst, J., et al. (2015). Pre- and postexposure efficacy of fully human antibodies against spike protein in a novel humanized mouse model of MERS-CoV infection. Proc. Natl. Acad. Sci. USA 112, 8738-8743. doi: 10.1073/ pnas. 1510830112

Paules, C. I., Lakdawala, S., McAuliffe, J. M., Paskel, M., Vogel, L., Kallewaard, N. L., et al. (2017). The hemagglutinin A stem antibody MEDI8852 prevents and controls disease and limits transmission of pandemic influenza viruses. $J$. Infect. Dis. 216, 356-365. doi: 10.1093/infdis/jix292

Petersen, E., Hui, D. S., Perlman, S., and Zumla, A. (2015). Middle East respiratory syndrome - advancing the public health and research agenda on MERS - lessons from the South Korea outbreak. Int. J. Infect. Dis. 36, 54-55. doi: 10.1016/j.ijid.2015.06.004

Pielak, R. M., and Chou, J. J. (2011). Influenza M2 proton channels. Biochim. Biophys. Acta 1808, 522-529. doi: 10.1016/j.bbamem.2010.04.015

Putri, W., Muscatello, D. J., Stockwell, M. S., and Newall, A. T. (2018). Economic burden of seasonal influenza in the United States. Vaccine 36, 3960-3966. doi: 10.1016/j.vaccine.2018.05.057

Rabaan, A. A. (2017). Middle East respiratory syndrome coronavirus: five years later. Expert Rev. Respir. Med. 11, 901-912. doi: 10.1080/17476348.2017.1367288

Rabaan, A. A., Alahmed, S. H., Bazzi, A. M., and Alhani, H. M. (2017). A review of candidate therapies for Middle East respiratory syndrome from a molecular perspective. J. Med. Microbiol. 66, 1261-1274. doi: 10.1099/ jmm.0.000565

Rossignol, J. F. (2009). Thiazolides: a new class of antiviral drugs. Expert Opin. Drug Metab. Toxicol. 5, 667-674. doi: 10.1517/17425250902988487

Rossignol, J. F., La Frazia, S., Chiappa, L., Ciucci, A., and Santoro, M. G. (2009). Thiazolides, a new class of anti-influenza molecules targeting viral hemagglutinin at the post-translational level. J. Biol. Chem. 284, 29798-29808. doi: $10.1074 /$ jbc.M109.029470

Rouan, M.-C., Gevers, T., Roymans, D., De Zwart, L., Nauwelaers, D., De Meulder, M., et al. (2010). Pharmacokinetics-pharmacodynamics of a respiratory syncytial virus fusion inhibitor in the cotton rat model. Antimicrob. Agents Chemother. 54, 4534-4539. doi: 10.1128/AAC.00643-10

Roymans, D., Rigaux, P., Kwanten, L., Vandesteene, C., Van Ginderen, M., Van Den Berg, J., et al. (2014). "Discovery of JNJ-53718678, a potent inhibitor 
of RSV" in 9th international respiratory syncytial virus symposium (Cape Town), 9-13.

Samuel, D., Xing, W., Niedziela-Majka, A., Wong, J. S., Hung, M., Brendza, K. M., et al. (2015). GS-5806 inhibits pre-to postfusion conformational changes of the respiratory syncytial virus fusion protein. Antimicrob. Agents Chemother. 59, 7109-7112. doi: 10.1128/AAC.00761-15

Schickli, J. H., Whitacre, D. C., Tang, R. S., Kaur, J., Lawlor, H., Peters, C. J., et al. (2015). Palivizumab epitope-displaying virus-like particles protect rodents from RSV challenge. J. Clin. Invest. 125, 1637-1647. doi: 10.1172/ JCI78450

Schnell, J. R., and Chou, J. J. (2008). Structure and mechanism of the M2 proton channel of influenza A virus. Nature 451, 591-595. doi: 10.1038/ nature 06531

Shahabi, A., Peneva, D., Incerti, D., McLaurin, K., and Stevens, W. (2017). Assessing variation in the cost of palivizumab for respiratory syncytial virus prevention in preterm infants. PharmacoEconomics-Open 2, 1-9. doi: 10.1007/ s41669-017-0042-3

Shalhoub, S., Farahat, F., Al-Jiffri, A., Simhairi, R., Shamma, O., Siddiqi, N., et al. (2015). IFN-alpha2a or IFN-beta1a in combination with ribavirin to treat Middle East respiratory syndrome coronavirus pneumonia: a retrospective study. J. Antimicrob. Chemother. 70, 2129-2132. doi: 10.1093/jac/dkv085

Shaw, M. L. (2017). The next wave of influenza drugs. ACS Infect. Dis. 3, 691-694. doi: 10.1021/acsinfecdis.7b00142

Sidwell, R. W., Barnard, D. L., Day, C. W., Smee, D. F., Bailey, K. W., Wong, M. H., et al. (2007). Efficacy of orally administered T-705 on lethal avian influenza A (H5N1) virus infections in mice. Antimicrob. Agents Chemother. 51, 845-851. doi: 10.1128/AAC.01051-06

Sivapalasingam, S., Caballero-Perez, D., Houghton, M., Yang, F., Davis, J., Gao, B., et al. (2015). "Phase 1 study evaluating safety, tolerability, pharmacokinetics and immunogenicity of REGN2222 in healthy adults: a new human monoclonal RSV-F antibody for RSV prevention" in Open forum infectious diseases (San Diego, CA: Oxford University Press).

Sleeman, K., Mishin, V. P., Guo, Z., Garten, R. J., Balish, A., Fry, A. M., et al. (2014). Antiviral susceptibility of variant influenza $A(H 3 N 2) v$ viruses isolated in the United States from 2011 to 2013. Antimicrob. Agents Chemother. 58, 2045-2051. doi: 10.1128/AAC.02556-13

Smee, D. F., Barnard, D. L., and Jones, S. M. (2016). Activities of JNJ63623872 and oseltamivir against influenza A H1N1pdm and $\mathrm{H} 3 \mathrm{~N} 2$ virus infections in mice. Antiviral Res. 136, 45-50. doi: 10.1016/j.antiviral.2016.10.009

Smee, D. F., Hurst, B. L., Wong, M. H., Bailey, K. W., Tarbet, E. B., Morrey, J. D., et al. (2010). Effects of the combination of favipiravir (T-705) and oseltamivir on influenza A virus infections in mice. Antimicrob. Agents Chemother. 54, 126-133. doi: 10.1128/AAC.00933-09

Stachulski, A. V., Santoro, M. G., Piacentini, S., Belardo, G., Frazia, S., Pidathala, C., et al. (2018). Second-generation nitazoxanide derivatives: thiazolides are effective inhibitors of the influenza A virus. Future Med. Chem. 10, 851-862. doi: 10.4155/fmc-2017-0217

Sun, Z., Pan, Y., Jiang, S., and Lu, L. (2013). Respiratory syncytial virus entry inhibitors targeting the F protein. Viruses 5, 211-225. doi: 10.3390/ v5010211

Takashita, E., Ejima, M., Ogawa, R., Fujisaki, S., Neumann, G., Furuta, Y., et al. (2016). Antiviral susceptibility of influenza viruses isolated from patients pre- and post-administration of favipiravir. Antiviral Res. 132, 170-177. doi: 10.1016/j.antiviral.2016.06.007

Takashita, E., Kiso, M., Fujisaki, S., Yokoyama, M., Nakamura, K., Shirakura, M., et al. (2015). Characterization of a large cluster of influenza A(H1N1)pdm09 viruses cross-resistant to oseltamivir and peramivir during the 2013-2014 influenza season in Japan. Antimicrob. Agents Chemother. 59, 2607-2617. doi: 10.1128/AAC.04836-14

Takashita, E., Morita, H., Ogawa, R., Nakamura, K., Fujisaki, S., Shirakura, M., et al. (2018). Susceptibility of influenza viruses to the novel cap-dependent endonuclease inhibitor Baloxavir Marboxil. Front. Microbiol. 9:3026. doi: 10.3389/fmicb.2018.03026

Taleb, S. A., Al Thani, A. A., Al Ansari, K., and Yassine, H. M. (2018). Human respiratory syncytial virus: pathogenesis, immune responses, and current vaccine approaches. Eur. J. Clin. Microbiol. Infect. Dis. 37, 1-11. doi: 10.1007/ s10096-018-3289-4

Tarbet, E. B., Maekawa, M., Furuta, Y., Babu, Y. S., Morrey, J. D., and Smee, D. F. (2012). Combinations of favipiravir and peramivir for the treatment of pandemic influenza A/California/04/2009 (H1N1) virus infections in mice. Antiviral Res. 94, 103-110. doi: 10.1016/j.antiviral.2012.03.001

Tharakaraman, K., Subramanian, V., Cain, D., Sasisekharan, V., and Sasisekharan, R. (2014). Broadly neutralizing influenza hemagglutinin stemspecific antibody CR8020 targets residues that are prone to escape due to host selection pressure. Cell Host Microbe 15, 644-651. doi: 10.1016/j. chom.2014.04.009

The PREVENT Study Group (1997). Reduction of respiratory syncytial virus hospitalization among premature infants and infants with bronchopulmonary dysplasia using respiratory syncytial virus immune globulin prophylaxis. Pediatrics 99, 93-99. doi: 10.1542/peds.99.1.93

Tian, D., Battles, M. B., Moin, S. M., Chen, M., Modjarrad, K., Kumar, A., et al. (2017). Structural basis of respiratory syncytial virus subtype-dependent neutralization by an antibody targeting the fusion glycoprotein. Nat. Commun 8:1877. doi: 10.1038/s41467-017-01858-w

Tilmanis, D., Van Baalen, C., Oh, D. Y., Rossignol, J. F., and Hurt, A. C. (2017). The susceptibility of circulating human influenza viruses to tizoxanide, the active metabolite of nitazoxanide. Antiviral Res. 147, 142-148. doi: 10.1016/j.antiviral.2017.10.002

Toovey, S., Wu, J., Wang, V., Griffin, P., Lau, A., and Elliot, S. (2015). "Safety and pharmacokinetics in healthy volunteers of the anti-RSV antiviral AK0529" in 1st international meeting on respiratory pathogens, September 3th, Singapore. International Society for Influenza and other Respiratory Virus Diseases (ISIRV).

Trevejo, J. M., Asmal, M., Vingerhoets, J., Polo, R., Robertson, S., Jiang, Y., et al. (2018). Pimodivir treatment in adult volunteers experimentally inoculated with live influenza virus: a phase IIa, randomized, double-blind, placebocontrolled study. Antivir. Ther. 23, 335-344. doi: 10.3851/IMP3212

Triana-Baltzer, G. B., Babizki, M., Chan, M. C., Wong, A. C., Aschenbrenner, L. M., Campbell, E. R., et al. (2010). DAS181, a sialidase fusion protein, protects human airway epithelium against influenza virus infection: an in vitro pharmacodynamic analysis. J. Antimicrob. Chemother. 65, 275-284. doi: 10.1093/jac/dkp421

Triana-Baltzer, G. B., Gubareva, L. V., Nicholls, J. M., Pearce, M. B., Mishin, V. P., Belser, J. A., et al. (2009). Novel pandemic influenza A(H1N1) viruses are potently inhibited by DAS181, a sialidase fusion protein. PLoS One 4:e7788. doi: 10.1371/journal.pone.0007838

Triana-Baltzer, G. B., Sanders, R. L., Hedlund, M., Jensen, K. A., Aschenbrenner, L. M., Larson, J. L., et al. (2011). Phenotypic and genotypic characterization of influenza virus mutants selected with the sialidase fusion protein DAS181. J. Antimicrob. Chemother. 66, 15-28. doi: 10.1093/jac/dkq387 Uehara, T., Keiko, K., Kawaguchi, K., Sato, C., Ishida, T., Hirotsu, N., et al. (2016). "S-033188, a small molecule inhibitor of cap-dependent endonuclease of influenza A and B virus, leads to rapid and profund viral load reduction" in Options for the control of influenza IX (Chicago, USA: ISIRV), 77.

Van Heeke, G., Allosery, K., De Brabandere, V., De Smedt, T., Detalle, L., and De Fougerolles, A. (2017). Nanobodies ${ }^{\circ}$ as inhaled biotherapeutics for lung diseases. Pharmacol. Ther. 169, 47-56. doi: 10.1016/j.pharmthera.2016.06.012

Wang, J., Pielak, R. M., McClintock, M. A., and Chou, J. J. (2009). Solution structure and functional analysis of the influenza B proton channel. Nat. Struct. Mol. Biol. 16, 1267-1271. doi: 10.1038/nsmb.1707

Wasserman, R. L., Greener, B. N., and Mond, J. (2017). RI-002, an intravenous immunoglobulin containing high titer neutralizing antibody to RSV and other respiratory viruses for use in primary immunodeficiency disease and other immune compromised populations. Expert Rev. Clin. Immunol. 13, 1107-1119. doi: 10.1080/1744666X.2017.1389647

Watanabe, T., Kiso, M., Fukuyama, S., Nakajima, N., Imai, M., Yamada, S., et al. (2013). Characterization of H7N9 influenza A viruses isolated from humans. Nature 501, 551-555. doi: 10.1038/nature12392

Wernery, U., Lau, S. K., and Woo, P. C. (2017). Middle East respiratory syndrome (MERS) coronavirus and dromedaries. Vet. J. 220, 75-79. doi: 10.1016/j. tvjl.2016.12.020

Widagdo, W., Okba, N. M. A., Stalin Raj, V., and Haagmans, B. L. (2017). MERS-coronavirus: from discovery to intervention. One Health 3, 11-16. doi: $10.1016 /$ j.onehlt.2016.12.001

World Health Organization. (2014). Position paper on collection and use of convalescent plasma or serum as an element in Middle East Respiratory Syndrome Coronavirus response. Available at: https://www.who.int/ bloodproducts/brn/BRN_PositionPaperConvPlasmaMERSCoV_March2014 pdf?ua $=1$ (Accessed March 11, 2014). 
World Health Organization. (2017). Influenza In Focus: Up to 650000 people die of respiratory diseases linked to seasonal flu each year. Available at: https://www.who.int/en/news-room/detail/14-12-2017-up-to-650-000-peopledie-of-respiratory-diseases-linked-to-seasonal-flu-each-year (Accessed April 17, 2019).

World Health Organization. (2019). Clinical mamagment of severe acute respiratory infection when MESR-CoV infection is suspected: interim guidance. Available at: http://www.who.int/iris/handle/10665/178529 (Accessed April 17, 2019).

Wu, X. X., Gao, H. N., Wu, H. B., Peng, X. M., Ou, H. L., and Li, L. J. (2015). Successful treatment of avian-origin influenza A (H7N9) infection using convalescent plasma. Int. J. Infect. Dis. 41, 3-5. doi: 10.1016/j. ijid.2015.10.009

Wu, H., Pfarr, D. S., Johnson, S., Brewah, Y. A., Woods, R. M., Patel, N. K., et al. (2007). Development of motavizumab, an ultra-potent antibody for the prevention of respiratory syncytial virus infection in the upper and lower respiratory tract. J. Mol. Biol. 368, 652-665. doi: 10.1016/j.jmb.2007.02.024

Wyde, P. R., Chetty, S. N., Timmerman, P., Gilbert, B. E., and Andries, K. (2003). Short duration aerosols of JNJ 2408068 (R170591) administered prophylactically or therapeutically protect cotton rats from experimental respiratory syncytial virus infection. Antiviral Res. 60, 221-231. doi: 10.1016/j.antiviral.2003.07.002

Wyde, P. R., Laquerre, S., Chetty, S. N., Gilbert, B. E., Nitz, T. J., and Pevear, D. C. (2005). Antiviral efficacy of VP14637 against respiratory syncytial virus in vitro and in cotton rats following delivery by small droplet aerosol. Antiviral Res. 178, 131-138. doi: 10.1016/j.antiviral.2005.06.009

Xing, Y., and Proesmans, M. (2019). New therapies for acute RSV infections: where are we? Eur. J. Pediatr. 68, 18-26. doi: 10.1007/s00431-018-03310-7

Yip, T. F., Selim, A. S. M., Lian, I., and Lee, S. M. (2018). Advancements in host-based interventions for influenza treatment. Front. Immunol. 9:1547. doi: 10.3389/fimmu.2018.01547

Zenilman, J. M., Fuchs, E. J., Hendrix, C. W., Radebaugh, C., Jurao, R., Nayak, S. U., et al. (2015). Phase 1 clinical trials of DAS181, an inhaled sialidase, in healthy adults. Antiviral Res. 123, 114-119. doi: 10.1016/j.antiviral.2015.09.008
Zhao, J., Perera, R. A., Kayali, G., Meyerholz, D., Perlman, S., and Peiris, M. (2015). Passive immunotherapy with dromedary immune serum in an experimental animal model for Middle East respiratory syndrome coronavirus infection. J. Virol. 89, 6117-6120. doi: 10.1128/JVI.00446-15

Zhu, Q., McAuliffe, J. M., Patel, N. K., Palmer-Hill, F. J., Yang, C.-F., Liang, B., et al. (2011). Analysis of respiratory syncytial virus preclinical and clinical variants resistant to neutralization by monoclonal antibodies palivizumab and/or motavizumab. J. Infect. Dis. 203, 674-682. doi: 10.1093/infdis/ jiq100

Zhurilo, N. I., Chudinov, M. V., Matveev, A. V., Smirnova, O. S., Konstantinova, I. D., Miroshnikov, A. I., et al. (2018). Isosteric ribavirin analogues: synthesis and antiviral activities. Bioorg. Med. Chem. Lett. 28, 11-14. doi: 10.1016/j. bmcl.2017.11.029

Zorc, J. J., and Hall, C. B. (2010). Bronchiolitis: recent evidence on diagnosis and management. Pediatrics 125, 2009-2092. doi: 10.1542/peds.2009-2092

Zumla, A., Chan, J. F., Azhar, E. I., Hui, D. S., and Yuen, K. Y. (2016). Coronaviruses - drug discovery and therapeutic options. Nat. Rev. Drug Discov. 15, 327-347. doi: 10.1038/nrd.2015.37

Zumla, A., Hui, D. S., and Perlman, S. (2015). Middle East respiratory syndrome. Lancet 386, 995-1007. doi: 10.1016/S0140-6736(15)60454-8

Conflict of Interest Statement: The authors declare that the research was conducted in the absence of any commercial or financial relationships that could be construed as a potential conflict of interest.

Copyright () 2019 Behzadi and Leyva-Grado. This is an open-access article distributed under the terms of the Creative Commons Attribution License (CC BY). The use, distribution or reproduction in other forums is permitted, provided the original author(s) and the copyright owner(s) are credited and that the original publication in this journal is cited, in accordance with accepted academic practice. No use, distribution or reproduction is permitted which does not comply with these terms. 